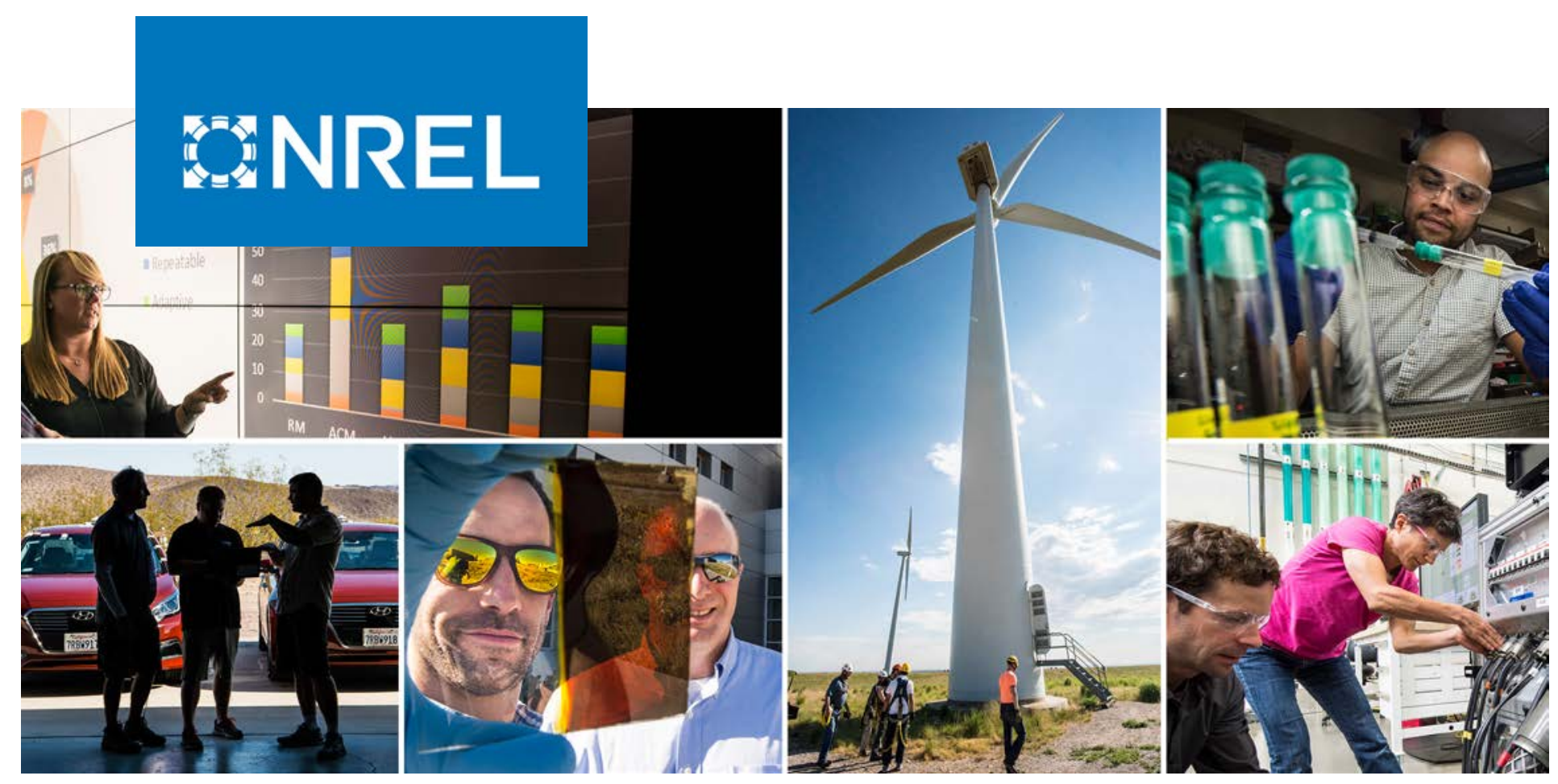

\title{
The Potential Impact of Offshore Wind Energy on a Future Power System in the U.S. Northeast
}

Philipp Beiter, Jessica Lau, Joshua Novacheck, Qing Yu, Gord Stephen, Jennie Jorgenson, Walter Musial, and Eric Lantz

National Renewable Energy Laboratory

NREL is a national laboratory of the U.S. Department of Energy Office of Energy Efficiency \& Renewable Energy

Operated by the Alliance for Sustainable Energy, LLC

This report is available at no cost from the National Renewable Energy Laboratory (NREL) at www.nrel.gov/publications.
Technical Report

NREL/TP-5000-74191

January 2020 


\section{BNREL}

\section{The Potential Impact of Offshore Wind Energy on a Future Power System in the U.S. Northeast}

Philipp Beiter, Jessica Lau, Joshua Novacheck, Qing Yu, Gord Stephen, Jennie Jorgenson, Walter Musial, and Eric Lantz

National Renewable Energy Laboratory

\section{Suggested Citation}

Beiter, Philipp, Jessica Lau, Joshua Novacheck, Qing Yu, Gord Stephen, Jennie Jorgenson, Walter Musial, and Eric Lantz. 2020. The Potential Impact of Offshore Wind Energy on a Future Power System in the U.S. Northeast. Golden, CO: National Renewable Energy Laboratory. NREL/TP-5000-74191. https://www.nrel.gov/docs/fy20osti/74191.pdf.

NREL is a national laboratory of the U.S. Department of Energy Office of Energy Efficiency \& Renewable Energy Operated by the Alliance for Sustainable Energy, LLC

This report is available at no cost from the National Renewable Energy Laboratory (NREL) at www.nrel.gov/publications.

Contract No. DE-AC36-08GO28308
Technical Report NREL/TP-5000-74191 January 2020

National Renewable Energy Laboratory 15013 Denver West Parkway Golden, CO 80401 303-275-3000 • www.nrel.gov 


\section{NOTICE}

This work was authored by the National Renewable Energy Laboratory, operated by Alliance for Sustainable Energy, LLC, for the U.S. Department of Energy (DOE) under Contract No. DE-AC36-08GO28308. Funding provided by the U.S. Department of Energy Office of Energy Efficiency and Renewable Energy Wind Energy Technologies Office. The views expressed herein do not necessarily represent the views of the DOE or the U.S. Government.

This report is available at no cost from the National Renewable Energy Laboratory (NREL) at www.nrel.gov/publications.

U.S. Department of Energy (DOE) reports produced after 1991 and a growing number of pre-1991 documents are available free via www.OSTI.gov.

Cover Photos by Dennis Schroeder: (clockwise, left to right) NREL 51934, NREL 45897, NREL 42160, NREL 45891, NREL 48097, NREL 46526.

NREL prints on paper that contains recycled content 


\section{Acknowledgments}

The authors would like to thank the many people who contributed to this report. For their support, we thank Dan Beals, Kerry Cheung, Charlton Clark, Alana Duerr, Jian Fu, Patrick Gilman, Gary Norton, and Rich Tusing from the U.S. Department of Energy. We would also like to thank Nick Grue, Daniel Laird, Heather Lammers, Trieu Mai and Gian Porro (National Renewable Energy Laboratory); Anthony Lopez (DigitalGlobe); Aaron Bloom (NextEra); Ryan Wiser and Andrew Mills (Lawrence Berkeley National Laboratory); David Coup and Christopher Hall (New York State Energy Research and Development Authority); Nils Bolgen, Tyler Studds, and Bill White (Massachusetts Clean Energy Center); Michael Giaimo and Michael Henderson (ISO New England); Michael Swider (New York Independent System Operator); and James Glennie (Consulate General of Denmark). Editorial support was provided by Sheri Anstedt. Any omissions are the sole responsibility of the authors. 


\section{List of Acronyms}

BOEM Bureau of Ocean Energy Management

CEMS Continuous Emissions Monitoring Systems

DOE U.S. Department of Energy

EPA U.S. Environmental Protection Agency

ERGIS Eastern Renewable Generation Integration Study

GW gigawatt

ISO independent system operator

$\mathrm{km} \quad$ kilometer

KPI key performance indicator

$\mathrm{kV} \quad$ kilovolt

LCOE levelized cost of energy

MW megawatt

MWh megawatt-hour

NGCC natural-gas combined-cycle

NGCT natural-gas combustion turbine

NREL National Renewable Energy Laboratory

NYSERDA New York State Energy Research and Development Authority

O\&M operation and maintenance

PPA power purchase agreement

PV solar photovoltaics

ReEDS Regional Energy Deployment System

RTO regional transmission operator

VRE variable renewable energy

WIND Wind Integration National Dataset 


\section{Executive Summary}

This study aims to understand and quantify the potential impact of offshore wind energy on a future electricity system in the U.S. Northeast. In this analysis, a detailed representation of the Northeast power system is adopted, using a generation portfolio for 2024 paired with offshore wind nameplate capacities of 0 gigawatts $(\mathrm{GW}), 2 \mathrm{GW}$, and $7 \mathrm{GW}$. The analysis identifies points of offshore wind interconnection in the ISO-New England and New York Independent System Operator control areas and uses hourly wind profiles from the Wind Integration National Dataset Toolkit. Hourly simulations of the 2024 power system operations show an ability to accommodate the prescribed offshore wind capacities by adapting the system's generation dispatch. Curtailment levels of offshore wind range between $4 \%$ and $5 \%$. Offshore wind generation displaces primarily natural-gas combined-cycle generation; however, requires increased flexibility from combined cycles through more frequent start-ups. The number of hours with transmission congestion increases because of offshore wind injection, with varying impact on a subregional level. Offshore wind's capacity credit was found to be $14.5 \%-28.3 \%$ and is lower than estimated in other large-scale power system studies, in part because this study considered a different weather year and a power system representation with higher shares of solar PV and onshore wind. The reliability contribution of resources is a topic area identified for more research and collaboration. The 7-GW scenario shows a reduction in locational marginal price of $11 \%$, with production cost savings of up to $18 \%$ compared to the $0-\mathrm{GW}$ scenario. 


\section{Table of Contents}

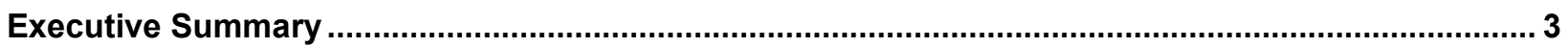

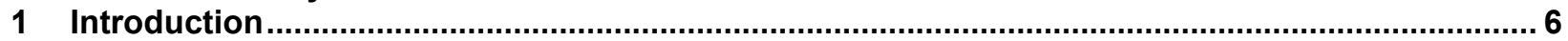

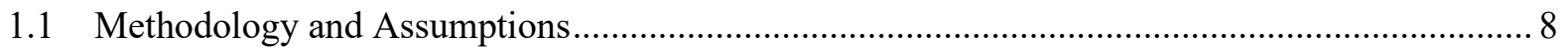

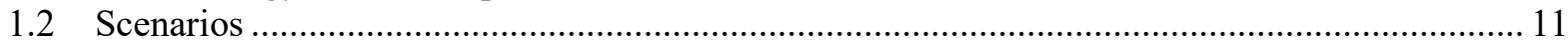

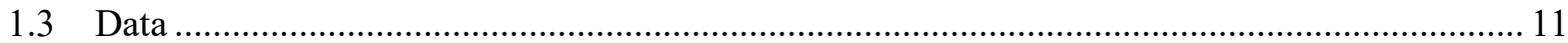

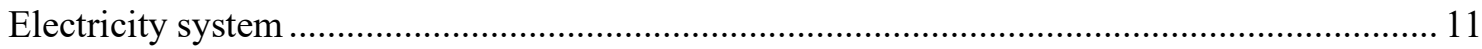

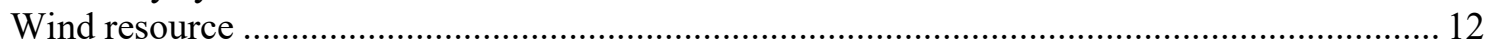

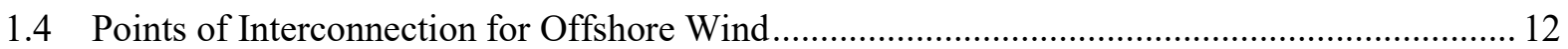

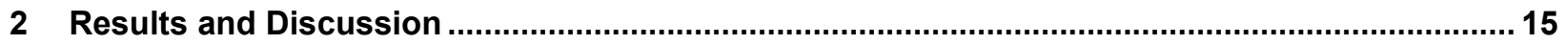

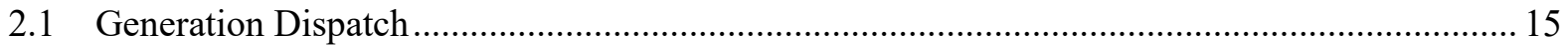

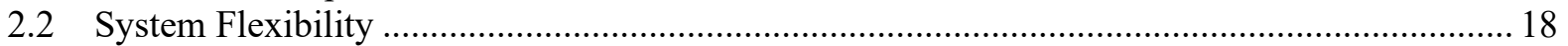

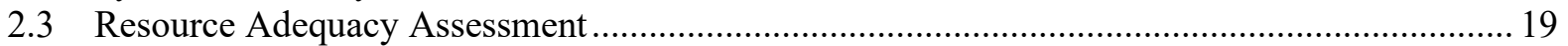

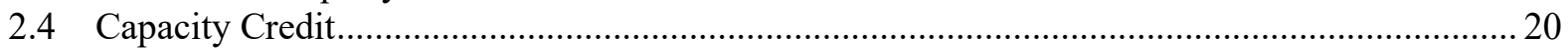

2.5 System Production Costs and Wholesale Electricity Prices...................................................... 22

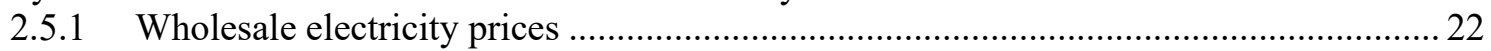

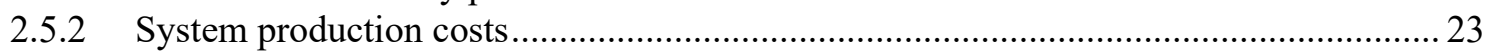

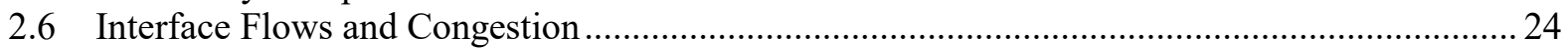

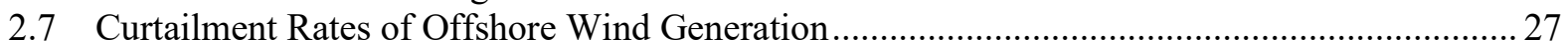

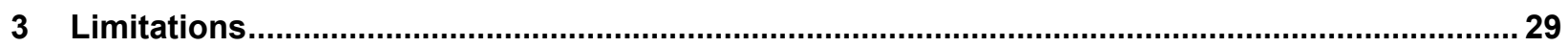

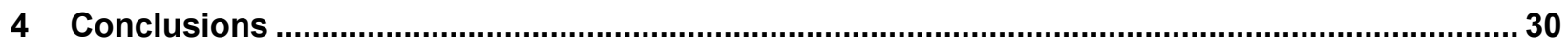

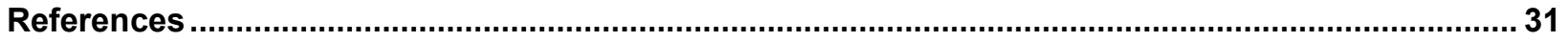

Appendix A .

A-1. Points of Offshore Wind Interconnection .................................................................... 34

A-2. Offshore Wind Gross Capacity Factor During Top 100 Peak Hours in ISO-NE and NYISO 


\section{List of Figures}

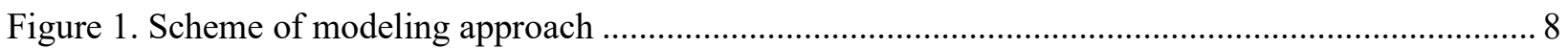

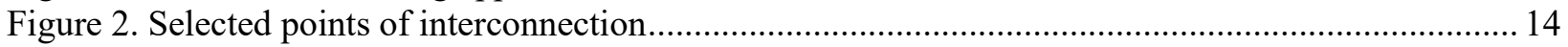

Figure 3. ISO-NE generation portfolio in 2024 (left) and difference compared to base scenario (0 GW)

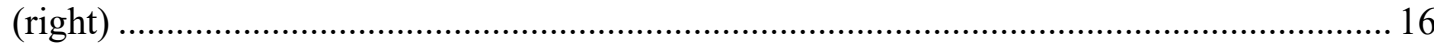

Figure 4. NYISO generation portfolio in 2024 (left) and difference compared to base scenario (0 GW)

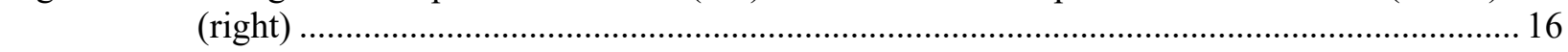

Figure 5. Types of generation providing spinning reserves ..................................................... 17

Figure 6. Difference in spinning reserve provision as compared to the 0-GW (base) scenario................. 17

Figure 7. Change in unit type start-ups in the 2-GW and 7-GW (2024) scenarios in the U.S. Northeast .. 18

Figure 8. Change in unit type start-ups in the 2-GW and 7-GW (2024) scenarios in the U.S. Northeast .. 19

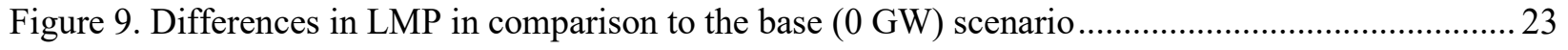

Figure 10. Change in near-zero LMPs …....................................................................................... 23

Figure 11. Differences in system production costs in comparison to the 0 -GW (base) scenario ............... 24

Figure 12. Difference in interface flows in U.S. Northeast between the 2-GW and 0-GW scenario ......... 25

Figure 13. Difference in interface flows in U.S. Northeast between the 2024 7-GW and 0-GW (base)

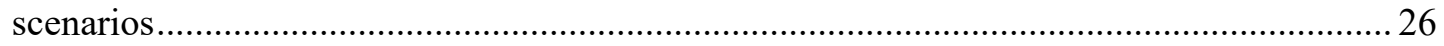

Figure 14. Share of congested hours in the U.S. Northeast (2-GW and 7-GW scenarios) ..................... 27

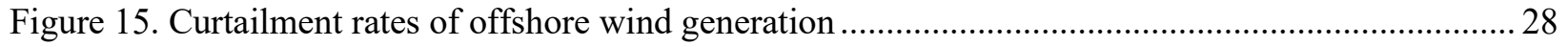

Figure A-1. Offshore wind gross capacity factor during top 100 peak hours in ISO-NE......................... 34

Figure A-2. Offshore wind gross capacity factor during top 100 peak hours in NYISO ........................... 35

\section{List of Tables}

Table 1. Relevant Offshore Wind Grid Analysis Studies .................................................................... 7

Table 2. Operationalization of Key Performance Indicators ................................................................ 9

Table 3. Modeled Scenarios in 2024 for the Combined NYISO and ISO-NE Control Areas ................... 11

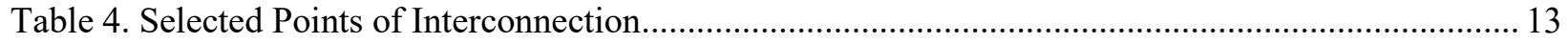

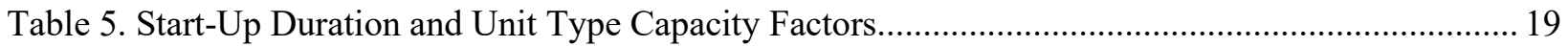

Table 6. LOLE Estimates for the Combined ISO-NE and NYISO System ............................................ 20

Table 7. Capacity Credit Estimates for Combined ISO-NE and NYISO System using Top 100 Peak Net

Load (Pre-Offshore Wind) Hours Methodology .................................................................. 22 


\section{Introduction}

The commencement of commercial operation at the Block Island Wind Farm (Rhode Island) in December 2016 marked a major milestone for the nascent U.S. offshore wind industry. With various projects at different stages of development, the industry is positioned to deliver nearly 8gigawatts (GW) of utility-scale generation ${ }^{1}$ in the U.S. Northeast by 2030 (Musial et al. 2016). This anticipated growth of offshore wind capacity along the U.S. Eastern Seaboard ${ }^{2}$ has led decision makers to shift focus toward understanding the potential impact of this technology on power system operations, rate payer electricity costs, and transmission infrastructure. Each generation type, including offshore wind, impacts the electricity system differently. In planning for a reliable electricity system, it is beneficial to examine a generator's ability and cost to supply electricity to consumers under different system operating conditions. ${ }^{3}$ Additional focus is required for hours of interest, which in the U.S. Northeast has historically been during summer peak hours and increasingly during winter cold spells when natural gas demand can exceed supply. Reliable power system operations also require provision of ancillary services, ${ }^{4}$ which help maintain system reliability under various operating conditions.

This study seeks to answer key questions for the combined ISO-NE and New York Independent System Operator (NYISO) control areas (hereafter referred to as the "U.S. Northeast"): (1) What is the extent of the potential impact from offshore wind on power system operations? (2) What conditions influence the impact of offshore wind generation to power system operations? (3) How does the potential impact from offshore wind compare across ISO and regional transmission operator (RTO) regions and to other variable renewable energy (VRE) ${ }^{5}$ generation types?

To answer these questions, the analysis examines different levels of offshore wind capacity scenarios in the U.S. Northeast in a 2024 power system representation using a PLEXOS production cost model detailed in Section 1.1. A range of power system studies have assessed the potential impact of offshore wind on the power system under various levels of offshore wind capacity (Table 1). Among recent studies, ISO-New England (ISO-NE) (2016) applies a production cost model and seems most comparable to this study in its approach and

\footnotetext{
${ }^{1}$ This estimate is based on the sum of the capacity from offshore wind projects that have signed a power purchase agreement (PPA) and from states that have set offshore wind procurement goals or made policy commitments with expected delivery of electricity before 2030. These include the Maryland Offshore Wind Renewable Energy Credit $(0.37 \mathrm{GW})$, the PPA signed between the Deepwater South Fork project and the Long Island Power Authority (0.09 GW), Massachusetts bill H4568 (1.6 GW), the New York State commitment (2.4 GW), and the New Jersey State commitment (3.5 GW).

${ }^{2}$ Various state offshore wind procurement goals (e.g., Massachusetts, Maryland, Delaware, New Jersey) and policy commitments (e.g., New York) at the state level are supporting this anticipated growth.

${ }^{3}$ Environmental and broader economic impacts are not considered in this study.

${ }^{4}$ Ancillary services "ensure reliability and support the transmission of electricity from generation sites to customer loads" (Beiter et al. 2018b). Its components and pricing vary among restructured electricity markets and may include services such as "load regulation, spinning reserve, non-spinning reserve, replacement reserve, and voltage support" (Beiter et al. 2018b).

${ }^{5}$ VRE can be defined as "renewable energy that is not stored prior to electricity generation; in most U.S. ISO/RTO markets, this includes primarily wind (including both land-based and offshore) and solar PV energy technologies" (Beiter et al. 2018b).
} 
methodology. ${ }^{6}$ It finds reductions in system production costs, wholesale electricity prices, and two major transmission interfaces being less constrained under the studied 1- and 2-GW scenarios for the ISO-NE control area. A recent study by Mills et al. (2018) analyzed the economic value of offshore wind along the U.S. eastern coastline by considering historical wholesale electricity market outcomes and renewable energy certificate prices at hundreds of possible transmission interconnection points. Mills et al. (2018) found a large variation in the average historical market value $(\$ 40 /$ megawatt-hour $[\mathrm{MWh}]$ to $\$ 110 / \mathrm{MWh}$ ) by project location, with the highest economic value among sites between New York and Massachusetts. The study also concluded that market value of offshore wind varies significantly from one year to another and identifies wholesale electricity and natural gas price reductions attributable to offshore wind through merit-order effects (i.e., offshore wind displacing higher-cost generation from the bid stack). In this analysis, we complement existing studies by assessing the potential operational impact of offshore wind under a future power system representation, with a variety of system performance indicators using the latest data and grid modeling capabilities.

Table 1. Recent Offshore Wind Grid Analysis Studies

\begin{tabular}{|l|l|l|l|}
\hline Study & $\begin{array}{l}\text { Atlantic Coastal } \\
\text { Region(s) }\end{array}$ & $\begin{array}{l}\text { Scenario } \\
\text { Year(s) }\end{array}$ & $\begin{array}{l}\text { Considered Offshore Wind Capacity } \\
\text { Scenarios (in addition to 0-GW base } \\
\text { scenario) }\end{array}$ \\
\hline Mills et al. (2018) & $\begin{array}{l}\text { ISO-NE, NYISO, PJM, Non- } \\
\text { ISO/RTO (Southeast Atlantic) }\end{array}$ & $\begin{array}{l}2007- \\
2016\end{array}$ & $100-\mathrm{MW}$ increments \\
\hline ISO-NE (2016) & ISO-NE & 2021 & $1 \mathrm{GW}$ to $2 \mathrm{GW}$ \\
\hline $\begin{array}{l}\text { U.S. Department } \\
\text { of Energy (2015) }\end{array}$ & CT, MA, ME, NH, NY, RI & 2020 & $0.70 \mathrm{GW}$ to $15.46 \mathrm{GW}$ \\
& & 2030 & \\
\hline ABB (2014) & ISO-NE, NYISO & 2050 & $13.1 \mathrm{GW}$ to $16 \mathrm{GW}$ \\
\hline NREL (2011) & ISO-NE & 2050 & $5 \mathrm{GW}$ to $11.04 \mathrm{GW}$ \\
\cline { 2 - 4 } & NYISO & 2024 & $2.62 \mathrm{GW}$ to $9.28 \mathrm{GW}$ \\
\hline
\end{tabular}

Factors that may influence the impact of offshore wind on power system operations include (but are not limited to) the coincidence of (forecasted and actual) offshore wind generation with load patterns, the prevailing local generation portfolio, the proximity to load, plant scale, costs, and performance under low probability events (e.g., power system outages, storms). These factors, and consequently the potential impact of offshore wind resources on electricity system operations, vary geographically and over time. For instance, increased generation from offshore wind (e.g., because of meteorological patterns such as the "sea breeze" effect [Dvorak et al. 2013]) might be able to offset the decline in generation from solar photovoltaics (PV) as solar radiation fades in the afternoon hours (i.e., commonly described as the "duck curve" effect [California Independent System Operator 2018]). This offsetting of declining generation by offshore wind during high demand hours of the day can add diversity for system needs, in addition to storage, demand response, or new-build transmission.

\footnotetext{
${ }^{6}$ ISO-NE also published a narrower study focused on understanding the potential impacts from adding $400 \mathrm{MW}$, $800 \mathrm{MW}$, and 1,600 MW to the New England power system during the 2017-18 cold spell (ISO-NE 2018).
} 


\subsection{Methodology and Assumptions}

The bulk of the analysis for this study was conducted during 2018 and reflects the best available data and assumptions available at that time. The authors conducted the analysis approach shown in Figure 1 using a detailed U.S. Northeast power systems representation in PLEXOS (\#1a in Figure 1), a production cost model developed by Energy Exemplar. Generators on the transmission network were modeled and dispatched to solve for minimum production costs while meeting system requirements for load and reserves in hourly unit commitment and dispatch. We sourced a large set of assumptions and data (\#2), including specifications of generators and their characteristics, a transmission network with defined limits, load representation, and other power system parameters for the Eastern Interconnection (which includes ISO-NE and NYISO) from the Eastern Renewable Generation Integration Study (ERGIS) (Bloom et al. 2016). Additionally, the transmission topology, generator retirements, generator thermal operating limits, and generator operating characteristics were updated from ERGIS as data became publicly available. For the Eastern Interconnection, generation capacity, location and type came from the 2026 "Summer Peak Power MMWG power flow case". Thermal operating limits for existing generators operating limits were updated by analyzing historical data from the U.S. Environmental Protection Agency (EPA) Continuous Emissions Monitoring Systems (CEMS) (Rossol et al. 2019).

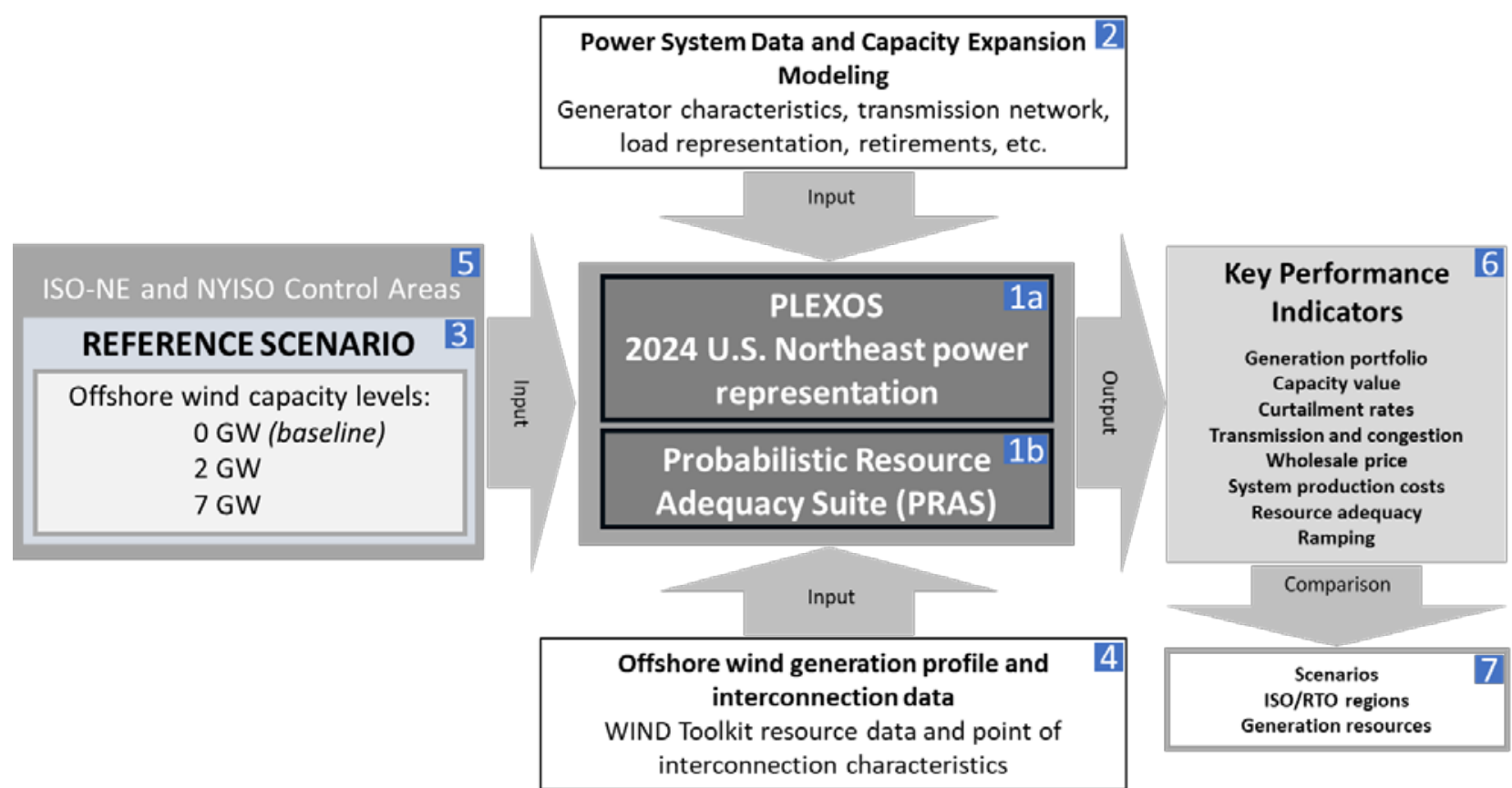

Figure 1. Scheme of modeling approach

The modeled power system represents a future electricity system generation portfolio in 2024 , which was combined with a set of prescribed offshore wind nameplate capacity of $0 \mathrm{GW}$ (base scenario), $2 \mathrm{GW}$, and $7 \mathrm{GW}$ (\#3) (Section 1.2). The varying offshore wind nameplate capacities are the only changes in the different scenarios. Installed generation capacity in 2024, except offshore wind, was determined through Regional Energy Deployment System capacity 
expansion modeling in a previous study using the "2016 Standard Scenarios"7 (Cole et al. 2016). Retirements by 2024 under the "2016 Standard Scenarios" were comprised of scheduled, agebased, and plant utilization retirements, which were not co-optimized with the prescribed offshore wind capacity additions. ${ }^{8}$ Offshore wind generation profiles were sourced from Wind Integration National Dataset (WIND) Toolkit data within current Bureau of Ocean Energy Management (BOEM) ${ }^{9}$ lease areas, wind energy areas, and Call Areas (Section 1.3). We identified points of interconnection (POI) for offshore wind (Section 1.4) that could accommodate the prescribed offshore wind capacity levels in principle (\#4). The analysis focused on the combined ISO-NE and NYISO control areas (\#5). ${ }^{10}$ Commercial-scale deployment of offshore wind generation resources appear likely by the mid- to late $2020 \mathrm{~s}$ in this region (Musial et al. 2019). We integrated market regions outside of the ISO-NE and NYISO control areas in a simplified representation to capture electricity import and export opportunities. Further, we assessed the impact from offshore wind on the U.S. Northeast power system across a set of key performance indicators (KPIs) (\#6), including capacity value, transmission interface flows and congestion hours, system production costs, wholesale prices, curtailment levels, and system ramping needs (Table 2). These are compared among the 2- and 7-GW offshore wind capacity-level scenarios, the study regions ISO-NE and NYISO, and various generation types (\#7).

Table 2. Operationalization of Key Performance Indicators

\begin{tabular}{|l|l|l|}
\hline Indicator & Metric & Unit \\
\hline $\begin{array}{l}\text { Wholesale } \\
\text { electricity } \\
\text { price }\end{array}$ & $\begin{array}{l}\text { Locational marginal price (LMP) } \\
\text { LMP is the marginal cost of supplying, at least cost, the next increment of electric demand at a } \\
\text { specific location (node) on the electric power network, considering both supply (generation/import) } \\
\text { bids and demand (load/export) offers and the physical aspects of the electric system, including } \\
\text { transmission and other operational constraints. }\end{array}$ & \$/MWh \\
\hline $\begin{array}{l}\text { Capacity } \\
\text { credit }\end{array}$ & $\begin{array}{l}\text { Capacity credit } \\
\text { Organized and centrally administered Forward Capacity Markets in PJM, NYISO, and ISO-NE are } \\
\text { designed to ensure that sufficient capacity is available to reliably meet planning reserve margins. } \\
\text { The contribution to overall system adequacy (i.e., the fraction of nameplate capacity that } \\
\text { contributes to the top peak net load hours) is a generator's capacity credit, which is calculated } \\
\text { differently among ISO/RTO market regions. In this study, the comparison between scenarios is } \\
\text { based on the: } \\
\text { 1) Aggregate offshore wind capacity factor during the system's top 100 net load hours } \\
\text { 2) Equivalent firm capacity based on system-level LOLE (PRAS) }\end{array}$ & \% \\
\hline $\begin{array}{l}\text { Transmission } \\
\text { and } \\
\text { congestion }\end{array}$ & $\begin{array}{l}\text { Interface flows } \\
\text { The flow of electricity between a defined set of transmission facilities that separate load zones and } \\
\text { ISO/RTO control zones (NYISO 2018a). } \\
\text { Sufficient transmission capacity can enable reliable electricity service to customers, relieve } \\
\text { congestion, facilitate robust wholesale market competition, integrate a diverse and changing } \\
\text { energy portfolio, and mitigate damage and limit customer outages during adverse conditions. }\end{array}$ & GW
\end{tabular}

\footnotetext{
${ }^{7}$ A more recent version of the "Standard Scenarios" has become available at the time of publication of this study but was not considered because the bulk of the analysis for this study was completed during 2018.

${ }^{8}$ Note that the New York State "Reforming the Energy Vision" targets were not considered for the "2016 Standard Scenarios."

${ }^{9}$ BOEM regulates energy and mineral resources on the U.S. Outer Continental Shelf, including offshore wind development.

${ }^{10}$ These control areas approximately represent the states of Connecticut, Maine, Massachusetts, New Hampshire, New York, Rhode Island, and Vermont.

${ }^{11}$ Source: Dent and Zachary (2013).
} 


\begin{tabular}{|c|c|c|}
\hline Indicator & Metric & Unit \\
\hline & $\begin{array}{l}\text { Interface congestion } \\
\text { Congestion creates constraints on the transmission system (i.e., NYISO [2018a]). }\end{array}$ & Hours \\
\hline $\begin{array}{l}\text { System } \\
\text { production } \\
\text { costs }\end{array}$ & $\begin{array}{l}\text { Total system production costs } \\
\text { The combined expenses from power generation for serving the load of a power system, including } \\
\text { those for start-up and shutdown, fuel, variable operation and maintenance, emissions, and } \\
\text { electricity imports. }\end{array}$ & $\$$ \\
\hline $\begin{array}{l}\text { Curtailment } \\
\text { levels }\end{array}$ & $\begin{array}{l}\text { Curtailment level } \\
\text { Curtailment is a prescribed reduction of scheduled capacity or energy delivery. Curtailment of } \\
\text { renewables and thermal generators can be the result of transmission congestion, minimum } \\
\text { operating levels of thermal generators or hydropower, or back-feeding in the distribution system. }\end{array}$ & $\%$ \\
\hline $\begin{array}{l}\text { System } \\
\text { flexibility } \\
\text { needs }\end{array}$ & $\begin{array}{l}\text { Unit type start-ups } \\
\text { Changes in unit type start-ups can signal the system's changing preference (based on generator } \\
\text { characteristics and economics) for different unit types. This metric is weighted by a unit's capacity } \\
\text { to enable comparisons of capacity impact with number of starts. } \\
\text { Unit type start-up duration } \\
\text { The amount of time that a unit type remains on-line. } \\
\text { For example, unit types that are typically started a low number of times in a year and stay on-line } \\
\text { for few (<48 hours) at a time, are often referred to as peaking units. }\end{array}$ & $\begin{array}{l}\text { Capacity } \\
\text { (GW)- } \\
\text { starts } \\
\text { Hours }\end{array}$ \\
\hline Reliability & $\begin{array}{l}\text { Type of spinning reserves } \\
\text { Spinning reserves are needed to serve all hours of load reliably (matching any energy imbalances } \\
\text { between generation at demand) and to maintain operating and contingency reserves. }\end{array}$ & $\begin{array}{l}\text { Generation } \\
\text { type }\end{array}$ \\
\hline
\end{tabular}

Source: Based on Beiter et al. (2018b)

In addition to exercising the PLEXOS production cost model (\#1a), we used a resource adequacy model for this analysis:- the Probabilistic Resource Adequacy Suite (PRAS) (\#1b) — to assess system supply adequacy through loss-of-load probability and expected unserved energy. ${ }^{12}$ PRAS represents the same transmission topology and generation resources. It does so by drawing Monte Carlo samples from time-dependent probability distributions describing generator availability as well as interregional power transfer constraints represented in a transportation network flow model. The model analyzes the distribution of possible system operating states ${ }^{13}$ to evaluate whether enough firm capacity exists to supply demand at some desired level of reliability. The result of such an analysis is a probabilistic metric, such as loss of load expectation (LOLE) (i.e., the expected value of total number of periods with shortfall across the time horizon studied) ${ }^{14}$ or expected unserved energy (i.e., the expected value of total energy shortfall over the time horizon) (North American Electric Reliability Corporation 2018).

In the PLEXOS production cost model, offshore wind, land-based wind, and solar resources (herein referred to as VRE resources) were assumed to have zero marginal costs and to be dispatchable up to their maximum available output. This configuration allows for curtailment of VRE to balance system demands and respect a variety of other generation and transmission constraints. We did not consider investment or production tax credits in the PLEXOS model for determining the operational value of a generation resource. This study was conducted in both the

\footnotetext{
${ }^{12}$ Resource adequacy models are typically used by utility and operating region system planners to ensure various future system buildouts have sufficient resources available to meet projected demand.

${ }^{13}$ For example, generator and transmission outages, generation from variable resources, and demand.

${ }^{14}$ In some literature, LOLE is reported as loss-of-load hours, if each individual analysis period corresponds to 1 hour and the total time horizon considered is 1 year.
} 
day-ahead and real-time operational phases of the electric power sector and at hourly resolution to capture the impacts of forecast error. ${ }^{15}$

\subsection{Scenarios}

The scenarios analyzed in this study for representing offshore wind in a 2024 power system (Table 3 ) were informed by a combination of previous studies (see Table 1) and an offshore wind market potential assessment for the U.S. Northeast. For estimating offshore wind market potential, project capacity was considered which either is contracted through a signed power purchase agreement (PPA) or is needed to meet a state procurement goal and policy commitment before 2030. ${ }^{16}$ The only exogenous change implemented in these scenarios was the prescribed capacity injection of offshore wind. ${ }^{17}$

Table 3. Modeled Scenarios in Year 2024 for the Combined NYISO and ISO-NE Control Areas

\begin{tabular}{|l|l|l|}
\hline \multicolumn{1}{|c|}{ Scenario } & \multicolumn{1}{|c|}{$\begin{array}{c}\text { Offshore Wind } \\
\text { Capacity }\end{array}$} & \multicolumn{1}{|c|}{$\begin{array}{c}\text { Offshore Wind Capacity Level from } \\
\text { Corresponding Study }\end{array}$} \\
\hline Base & $0 \mathrm{GW}$ & N/A \\
\hline I & $2 \mathrm{GW}$ & $\begin{array}{l}\text { ISO-NE (2015) 2021 “High offshore wind" } \\
\text { scenario }\end{array}$ \\
\hline II & $7 \mathrm{GW}$ & DOE (2015) Wind Vision 2030 Study Scenario \\
\hline
\end{tabular}

\subsection{Data}

\subsubsection{Electricity system}

The market and subregion load profiles combine 1) 2012 load data published by RTOs and independent system operators (ISOs) (Bloom et al. 2016), and 2) from Federal Energy Regulatory Commission Form 714 for 2012 hourly load data for non-RTO/ISO regions (Federal Energy Regulatory Commission 2016). The load profiles are meteorologically consistent with wind and solar data sets used in this study.

We determined operating reserve requirements dynamically based on methods used in (Bloom et al. 2016). A reserve product is represented in the PLEXOS production cost model to regulate reserve and contingency reserve requirements. Reserves are procured on a regional basis for NYISO and ISO-NE.

The transmission network was based on the power flow cases maintained by the North American Electric Reliability Corporation's Eastern Interconnection Reliability Assessment Group,

\footnotetext{
${ }^{15}$ Note that the offshore wind resource data from WIND Toolkit were processed with hourly resolution; subhourly dispatch modeling was not conducted.

${ }^{16}$ These include the Maryland Offshore Wind Renewable Energy Credit $(0.37 \mathrm{GW})$, the PPA signed between the Deepwater South Fork project and the Long Island Power Authority (0.09 GW), Massachusetts bill H4568 (1.6 GW), the New York State commitment (2.4 GW), and the New Jersey State commitment (3.5 GW) (Beiter et al. 2018a).

${ }^{17}$ The prescribed offshore wind scenario levels correspond to $6.3 \%$ (2-GW study scenario) and $22.2 \%$ (7-GW study scenario) of forecasted summer (peak) capacity of $31.5 \mathrm{GW}$ in ISO-NE (ISO-NE 2017) in 2024. For the same year, the corresponding levels in NYISO are 5.9\% (2-GW study scenario) and 20.6\% (7-GW study scenario) of $33.9 \mathrm{GW}$ (NYISO 2017 "baseline scenario").
} 
Multiregional Modeling Working Group 2026 "summer case." Generators and their operating characters were adopted from the Eastern Renewable Generation Integration Study (Bloom et al. 2016).

\subsubsection{Wind resource}

Wind resource data for this study were derived from the WIND Toolkit (Draxl et al. 2015) and processed using the Renewable Energy Potential (reV) model (National Renewable Energy Laboratory 2018). ${ }^{18}$ The WIND Toolkit "technoeconomic" data includes meteorological conditions and turbine power for more than 126,000 sites in the continental United States, including offshore sites, for the years 2007-2013. Gross capacity factors were calculated using a representative power curve for a generic NREL-modeled 6-MW offshore wind turbine (Beiter et al. 2016). The WIND Toolkit also includes a forecast data set at 1-hour, 4-hour, 6-hour, and 24hour forecast horizons.

From the expansive set of WIND Toolkit resource sites (based on a 2-kilometer spacing), offshore wind sites were limited to site locations within the current BOEM lease areas, wind energy areas, and Call Areas in the U.S. Northeast, as documented in Musial et al. (2017). Hourly time-synchronized data for load, offshore wind, land-based wind, and PV from weather year 2012 were used. For load, 2012 was found to be a "normal" weather year, within the WIND Toolkit data range 2007-2013. Additionally, 24-hour-ahead forecast data for offshore and landbased wind were developed. Because of limited offshore wind forecast data, the sites were matched to the nearest land-based WIND Toolkit site and their hourly forecast errors were used to develop 24-hour-ahead offshore wind forecasts.

In a next step, we ranked sites by their economic viability (as proxied by the metric "net value" established in Beiter et al. (2017). We chose those sites with the highest "net value" in increments of $16 \mathrm{MW}^{19}$ until the prescribed offshore wind capacity scenarios of $2 \mathrm{GW}$ and $7 \mathrm{GW}$ were met.

\subsection{Points of Interconnection for Offshore Wind}

The location of interconnection can influence a generator's impact on the local power system and revenue opportunities. For example, new generation might relieve a locally constrained power system and change interface flows effectively reducing congestion. Conversely, a generator may be dispatched down or curtailed if the connecting lines are severely congested during the time of generation. Offshore wind is geographically positioned to consider (offshore) transmission ties directly into major U.S. coastal load centers (e.g., New York City, Boston, Long Island), which could alleviate some already congested transmission paths (e.g., from upstate New York into New York City or from New York City into Long Island). Among the coastal points of interconnection, several retired or soon-to-retire generators are considered (e.g., at Brayton Point [Massachusetts Clean Energy Center 2014]) because of existing transmission and interconnection infrastructure. These interconnection locations have the ability to facilitate the

\footnotetext{
18 The WIND Toolkit data set was created using wind speed data at a 100-m hub height and combined with a 6-MW generic turbine power curve documented in Musial et al. (2016). This yields an hourly estimate of power production for each turbine site. The offshore wind power output data from the WIND Toolkit was then reduced by $16.7 \%$ to account for wake, electrical, and other losses.

${ }^{19}$ Each site modeled in the Wind Toolkit has an estimated capacity of $16 \mathrm{MW}$ (Hodge 2016).
} 
injection of large amounts of electricity and have previous interconnection agreements with the local transmission owner and ISO.

For identifying potential points of offshore wind interconnection, the prescribed offshore wind capacity levels were assigned to ISO-NE and NYISO in proportion to the offshore wind project pipeline from Musial et al. (2016) that is associated with states within ISO-NE and NYISO.

Existing POI above 345 kilovolts $(\mathrm{kV})$ and buses from power plants scheduled for retirement by 2024 (ABB 2018) were evaluated and selected under consideration of possible POI identified by Wilson (2011). The selected POI are shown in Table 4 and Figure 2 (see Appendix A for a more detailed description).

Table 4. Selected Points of Interconnection

\begin{tabular}{|l|l|l|}
\hline \multicolumn{1}{|c|}{ Bus Name } & $\begin{array}{l}\text { Max. Available } \\
\text { Capacity (MW) }\end{array}$ & \multicolumn{1}{|c|}{$\begin{array}{c}\text { Used } \\
\text { Capacity } \\
\text { (MW) }\end{array}$} \\
\hline 2-GW Scenario & \multicolumn{2}{l|}{} \\
\hline $\begin{array}{l}\text { Brayton Point (345 kV) } \\
\text { (retirement) }\end{array}$ & 1,900 & 1,330 \\
\hline GOWANUS 42SR (345 kV) & 800 & 670 \\
\hline TOTAL & $\mathbf{2 , 7 0 0}$ & $\mathbf{2 , 0 0 0}$ \\
\hline 7-GW Scenario & \multicolumn{2}{|l}{} \\
\hline $\begin{array}{l}\text { Brayton Point (345 kV) } \\
\text { (retirement) }\end{array}$ & 1,900 & 1,770 \\
\hline GOWANUS 42SR (345 kV) & 800 & 670 \\
\hline Millstone (345 kV) & 5,852 & 2,900 \\
\hline Fresh Kills (345 kV) & 2,404 & 1,660 \\
\hline TOTAL & $\mathbf{1 0 , 9 6 0}$ & $\mathbf{7 , 0 0 0}$ \\
\hline
\end{tabular}



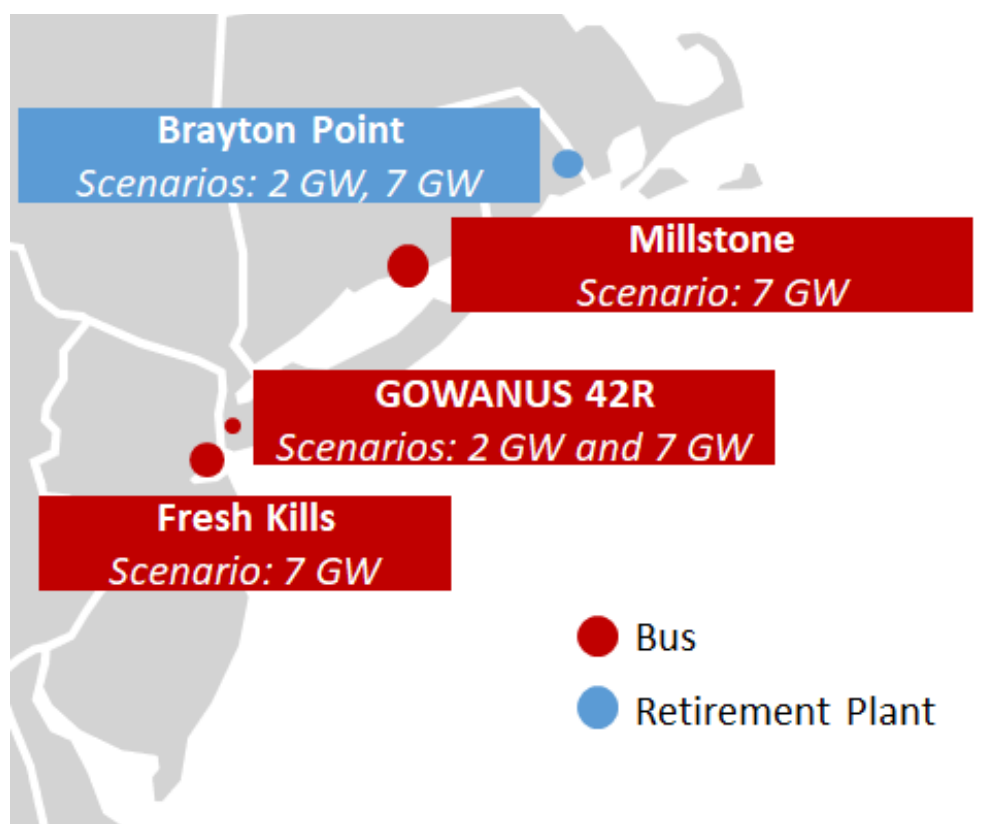

Bus

Retirement Plant

Figure 2. Selected points of interconnection

Note: The size of the points represents total POI capacity. 


\section{Results and Discussion}

We compared results between the offshore wind scenarios (referred to as " $2 \mathrm{GW"}$ " and "7 GW" hereafter) relative to the $0-\mathrm{GW}$ (base) scenario, the study regions ISO-NE and NYISO, ${ }^{20}$ and various generation types.

\subsection{Generation Dispatch}

Production cost models simulate power system operations by minimizing power system production costs ${ }^{21}$ under a set of power system constraints. Injecting offshore wind capacity at the prescribed 2-GW and 7-GW capacity levels (Table 3) into the modeled ISO-NE and NYISO power system configuration at a marginal cost of $\$ 0 / \mathrm{MWh}$ results in a displacement of other generation types with higher marginal costs and an increase in ISO/RTO net exports ${ }^{22}$ compared $^{2}$ to the $0-\mathrm{GW}$ (base) scenario.

As depicted in Figure 3 and Figure 4, generation in ISO-NE and NYISO in the 2024 0-GW (base) scenario predominately comprises thermal (natural-gas combined-cycle [NGCC]) and nuclear generation. ${ }^{23}$ The NYISO annual energy dispatch (Figure 4) is more heavily reliant upon hydropower generation in comparison to ISO-NE. Both ISO/RTO regions are importers of electricity from neighboring electricity markets to meet their load of approximately 139 (ISO$\mathrm{NE}$ ) and 179 terawatt-hours (NYISO). Under the 2-GW and 7-GW scenarios, offshore wind provides $4.0 \%$ and $13.5 \%$ of total energy consumption in ISO-NE, respectively; in NYISO, the corresponding share of total consumption is $1.4 \%$ (2-GW scenario) and 5.1\% (7-GW scenario). The prescribed offshore wind capacity primarily displaces NGCC in both ISO/RTO regions compared to the $0-\mathrm{GW}$ (base) scenario (-7\% under the $2-\mathrm{GW}$ and $-23 \%$ under the $7-\mathrm{GW}$ scenario). The displacement of coal generation corresponds to $-2 \%$ (2-GW scenario) and $-20 \%$ (7-GW scenario) in relative terms compared to the $0-\mathrm{GW}$ (base) scenario. Storage usage grows by 4\% (2-GW scenario) and 33\% (7-GW scenario), respectively. Curtailment levels are discussed in Section 2.7. Both ISO/RTO regions remain net importers of electricity, which is further discussed in Section 2.6.

\footnotetext{
${ }^{20}$ When results do not indicate ISO-NE or NYISO specifically, the reported results refer to the combined ISO-NE and NYISO control areas.

${ }^{21}$ Note that fixed costs are not considered for power system optimization.

22 "Net exports" are defined as the exported capacity minus imported capacity of electricity.

23 These results are in line with ISO-NE (2017) and NYISO (2018b).
} 


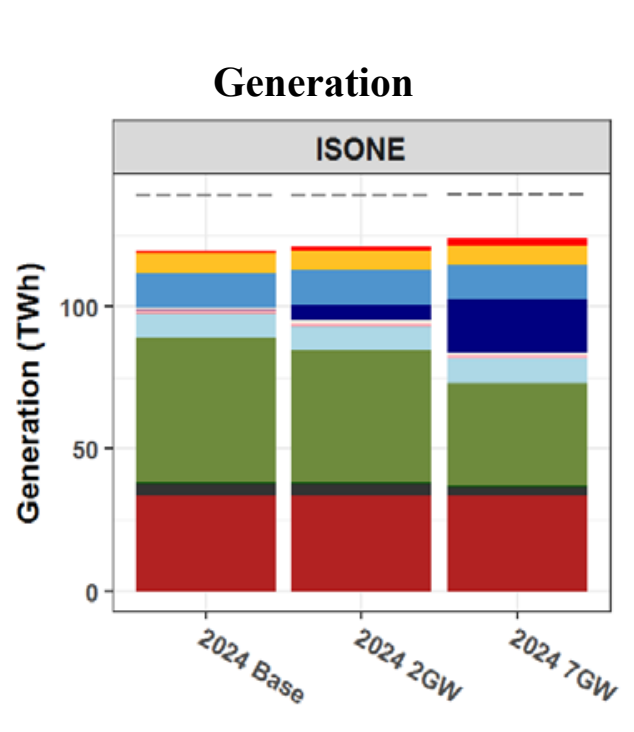

\section{ISO-NE}

Difference from Base Scenario (0 GW)

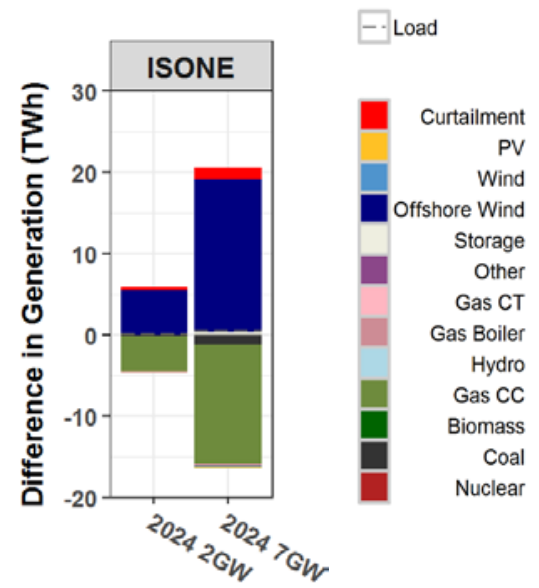

Figure 3. ISO-NE generation portfolio in 2024 (left) and difference compared to base scenario (0 GW) (right)

\section{NYISO}

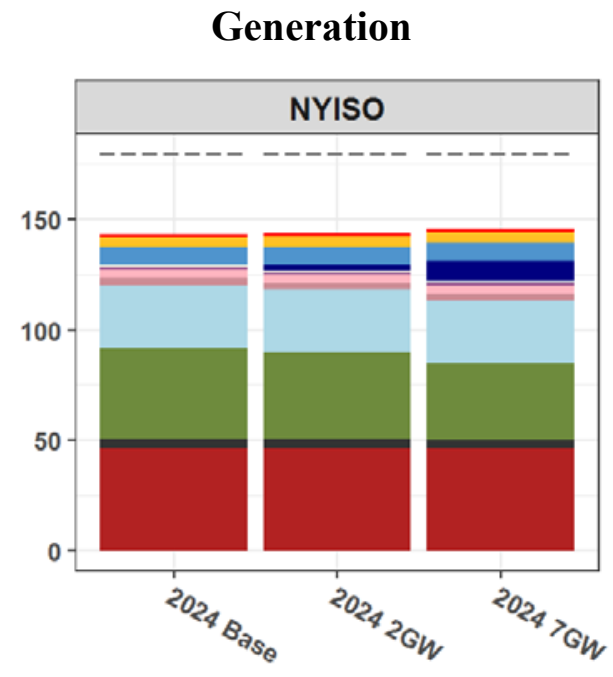

\section{Difference from Base Scenario (0 GW)}

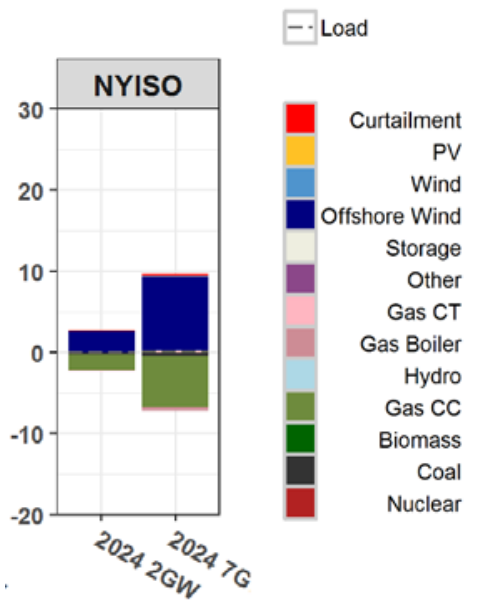

Figure 4. NYISO generation portfolio in 2024 (left) and difference compared to base scenario (0 GW) (right)

Note: In the figure to the right, "Gas CT" is natural-gas combustion turbine and "Gas CC" is natural-gas combined-cycle.

In the modeled 2024 system representation, all hours of load are reliably served. In addition to meeting load at all times, the system needs to maintain operating and contingency reserves. ${ }^{24}$ In

${ }^{24}$ This is to prepare for large contingencies and to match energy imbalances between generation and demand, which may occur from unexpected transmission outages or the inherent variability and uncertainty of VRE, including offshore wind. 
this study, all resources except land-based wind and PV are eligible to provide reserves, including offshore wind, which can provide reserves by curtailing energy. ${ }^{25}$ The model is calibrated so that offshore wind resource are able to provide spinning reserve only when curtailed. The primary generation type providing spinning reserves in the $0-\mathrm{GW}$ (base) scenario is NGCC in the U.S. Northeast, supplemented by a variety of other generation types, mostly coal-fired and natural-gas combustion turbines (NGCT) (Figure 5). As offshore wind capacity increments are injected into the power system under the 2-GW and 7-GW scenarios (Figure 6), a growing share of spinning reserves is provided by offshore wind reducing the overall amount of reserves provided by other generation types, mostly NGCC. In the 7-GW scenario in NYISO, the reduction of NGCC spinning reserves are replaced by nearly equal shares of NGCT and offshore wind.

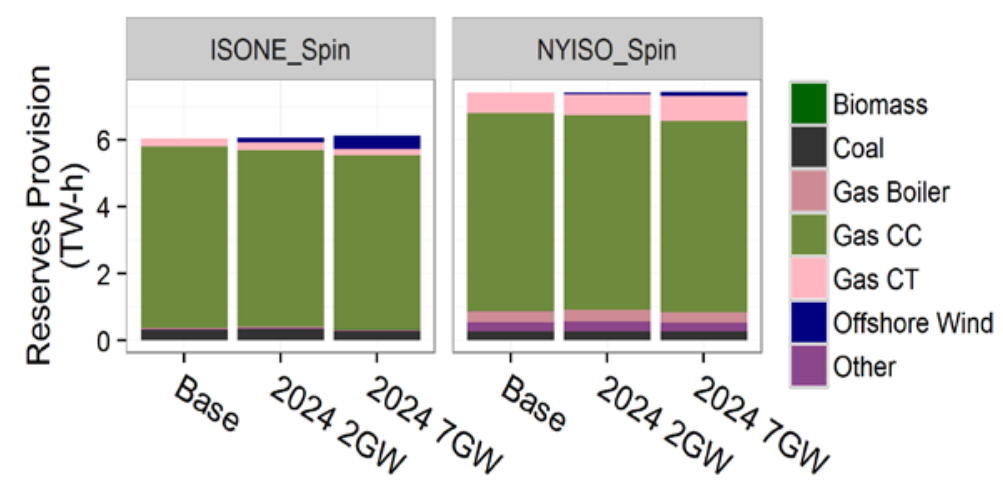

Figure 5. Types of generation providing spinning reserves Note: "Other" includes all oil generators (oil CC, oil boiler, oil CT).

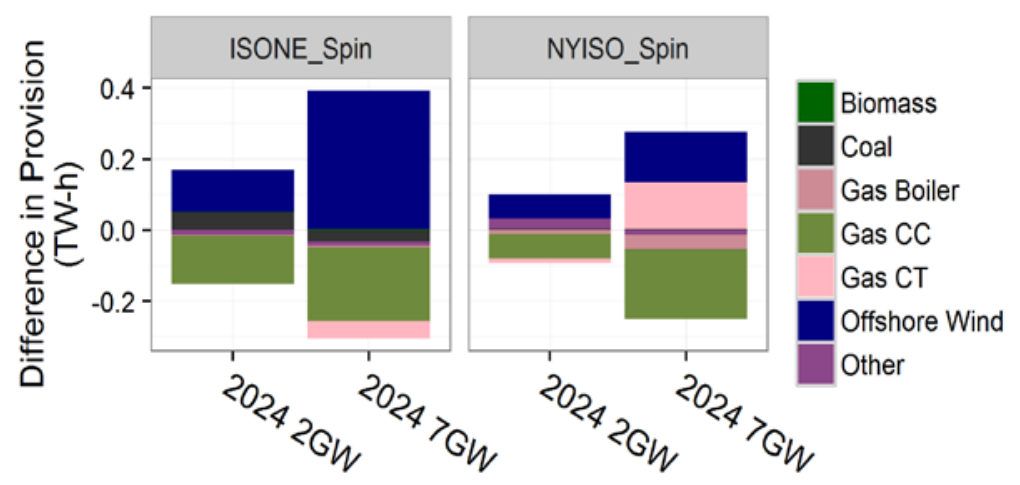

Figure 6. Difference in spinning reserve provision as compared to the $\mathbf{0 - G W}$ (base) scenario Note: "Other" includes all oil generators (oil CC, oil boiler, oil CT).

\footnotetext{
${ }^{25}$ It has been demonstrated that land-based wind and PV can provide reserves. However, much of the land-based wind and PV modeled in this study represent existing units, which do not have the proper inverters or controls to participate in reserve markets. Future work should examine the impact of allowing other types of VRE to provide reserves.
} 


\subsection{System Flexibility}

A potential impact of the inherent variability of offshore wind is the need for increased flexibility. System flexibility is provided by many types of generators, through ramping, startups, and shutdown. The requirement for flexibility can result in increased production costs, through starting up a NGCT unit (with associated start-up costs) or ramping up a NGCC unit quickly (with associated additional fuel cost). The variability from offshore wind may increase the ramping demand from different generating units, which may be especially impactful (e.g., in terms of operating costs) on those that were not designed for frequent start-ups and shutdowns. "Capacity starts" is a representation of generator starts weighted by their unit nameplate capacity. In the 0 -GW (base) scenario, more than $86 \%$ of GW-starts are provided by a combination of NGCC and pumped hydropower storage (PS) (Figure 7).

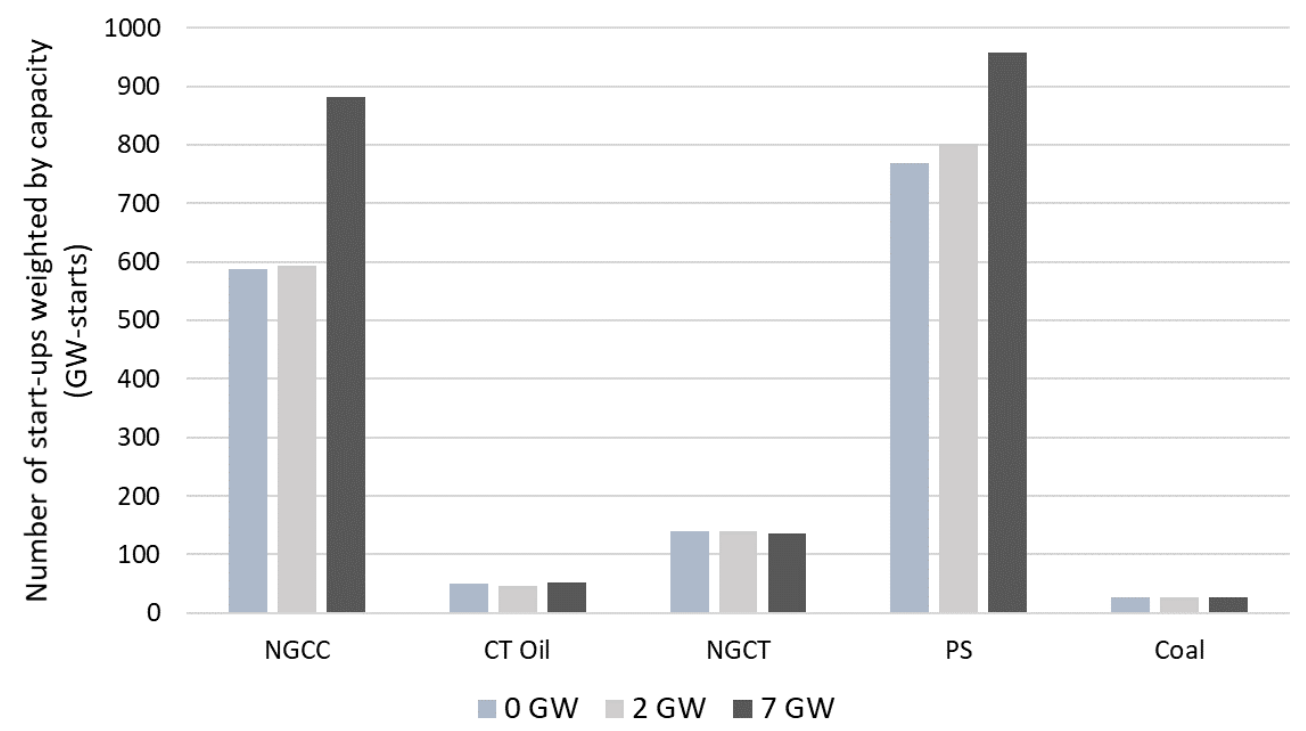

Figure 7. Change in unit type start-ups in the 2-GW and 7-GW (2024) scenarios in the U.S. Northeast

Figure 8 shows the change in generator start-ups as compared to the base scenario $(0 \mathrm{GW})$. GWstarts remain relatively constant under the 2-GW scenario. Under the 7-GW scenario, there is an increase of NGCC (by nearly 50\%) and pumped hydropower storage (by more than $24 \%$ ) GWstarts. 


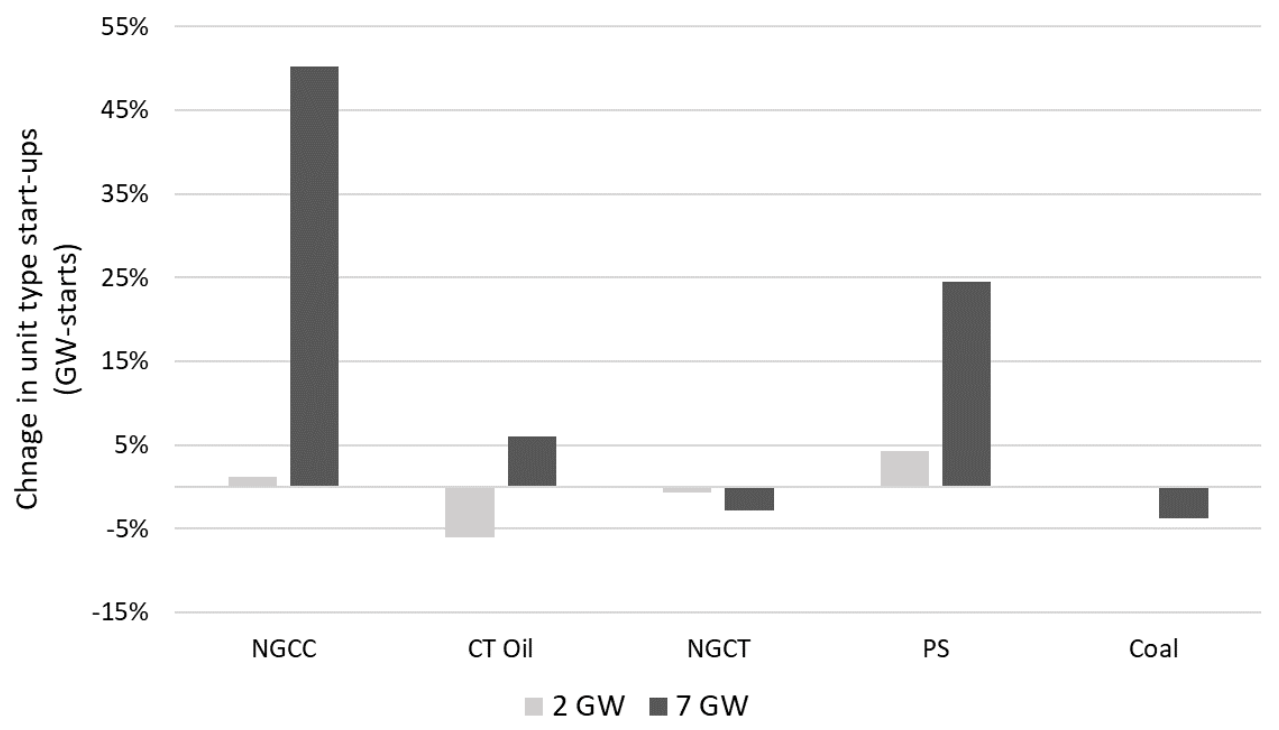

Figure 8. Change in unit type start-ups in the 2-GW and 7-GW (2024) scenarios in the U.S. Northeast

Correspondingly, the average number of hours that a unit is on-line after a start-up is relatively constant across thermal plants and PS in the 2-GW scenario but decreases for NGCC (-34\%) in the 7-GW scenario (Table 5), indicating increased cycling activity. As shown in Table 5, the capacity factor of thermal units and PS while on-line (or alternatively, the average dispatch point) overall stays relatively flat. The average capacity factor of NGCC, coal, and NGCT all decrease, because they are all being displaced by offshore wind.

These results suggest that the largest demand of system flexibility from the impact of increasing offshore wind is the NGCC fleet. NGCC experienced increased starts and decreased hours online per start, indicating more frequent cycling. Note that increased O\&M costs from increased start-ups to accomodate the prescribed offshore wind injections are not considered (e.g., as part of the system production costs in section 2.5.2).

Table 5. Start-Up Duration and Unit Type Capacity Factors

\begin{tabular}{|c|c|c|c|c|c|c|c|c|c|c|c|c|c|c|c|}
\hline Scenario & \multicolumn{1}{|c|}{$\begin{array}{c}\text { Average Hours On-line } \\
\text { Per Start }\end{array}$} & \multicolumn{10}{|c|}{$\begin{array}{c}\text { Average Capacity Factor } \\
\text { (\%) }\end{array}$} & \multicolumn{1}{c|}{ Capacity Factor While On- } \\
line (\%)
\end{tabular}

\subsection{Resource Adequacy Assessment}

Assessing resource adequacy of a power system gives an indication of reliability level.

Comparing a system before and after the addition of a new generator can assess a generator's contribution toward resource adequacy. Using PRAS, this study quantified the incremental system reliability benefit provided by that new resource, taking into consideration both the 
availability of the resource every hour over a year, reflecting peak load and net load periods, and its deliverability given transmission system constraints. Because of capacity resources exceeding demand in the U.S. Northeast model (even in the 2024 base scenario), additional capacity interconnected (regardless of capacity contribution, even at $100 \%$ firm) was not observed to decrease LOLE. The Long Island region is limited by local area generation and a transmissionconstrained local system to import energy, and ultimately incurs most of the U.S. Northeast's LOLE in the model. This study's base model configuration did not interconnect any offshore wind directly to Long Island. An additional resource adequacy sensitivity was conducted to test the benefit of 1) increasing the transmission capability between New York City (NYC) and Long Island (LI), and 2) interconnecting offshore wind directly to Long Island instead of NYC.

Table 6 summarizes the LOLE results from the analysis. Regardless of offshore wind capacity, LOLE of the U.S. Northeast remains at approximately 6.6 hours per year. It should be noted that this effect is driven by Long Island's generation resources and transmission topology and is not specific to wind or its variable nature; even a fully dispatchable resource connected in NYC would be unable to alleviate a potential load shortfall on Long Island. An additional sensitivity case that was tested implied adding 50\% transmission capacity between NYC and LI, which resulted in LOLE to decrease to about 0.07 hours per year. If offshore wind generation (or any other generation type) was assumed to be interconnected into the LI region directly, then each increment of offshore wind is shown to benefit LOLE for the LI region. These incremental resource adequacy benefits were calculated by PRAS to correspond to equivalent firm capacities of $31.6 \%(2 \mathrm{GW})$ and $15.4 \%(7 \mathrm{GW})$.

Table 6. LOLE Estimates for the Combined ISO-NE and NYISO System

\begin{tabular}{|c|c|c|c|c|c|}
\hline \multirow[b]{2}{*}{ Method } & \multirow[b]{2}{*}{$\begin{array}{l}\text { Metric } \\
\text { (unit) }\end{array}$} & \multirow[b]{2}{*}{ Scenario } & \multicolumn{3}{|c|}{ Resource Adequacy Sensitivities } \\
\hline & & & $\begin{array}{l}\text { Reference } \\
\text { Transmission } \\
\text { and } \\
\text { Interconnection }\end{array}$ & $\begin{array}{l}50 \% \text { Additional } \\
\text { Transmission } \\
\text { Capacity } \\
\text { Between NYC } \\
\text { and LI }\end{array}$ & $\begin{array}{c}\text { NYC Offshore } \\
\text { Wind } \\
\text { Generator } \\
\text { Sites } \\
\text { Connected to } \\
\text { LI }\end{array}$ \\
\hline \multirow{3}{*}{$\begin{array}{c}\text { Resource } \\
\text { Adequacy } \\
\text { Suite } \\
\text { (PRAS) }\end{array}$} & \multirow{3}{*}{$\begin{array}{c}\text { LOLE } \\
\text { (hours/year) }\end{array}$} & $\begin{array}{c}\text { Base (0 } \\
\text { GW) }\end{array}$ & $6.642 \pm 0.006$ & $0.0718 \pm 0.0008$ & $6.645 \pm 0.006$ \\
\hline & & $2 \mathrm{GW}$ & $6.632 \pm 0.006$ & $0.0710 \pm 0.0008$ & $1.433 \pm 0.003$ \\
\hline & & $7 \mathrm{GW}$ & $6.646 \pm 0.006$ & $0.0701 \pm 0.0008$ & $0.376 \pm 0.002$ \\
\hline
\end{tabular}

Note: \pm indicates the standard error of the estimate.

\subsection{Capacity Credit}

Beyond assessing a system's reliability through resource adequacy, capacity credit refers to specific benefits of a generator or resource type as it relates to its contribution to meeting demand. Power systems infrastructure has traditionally been planned to meet peak hours. An attribute of offshore wind and other VRE is their inherent variability, which has given rise to questions whether grid operators could rely on VRE during real-time operational demands. These real-time operational demands are particularly relevant during peak hours when the grid is 
in its most demanding state. ${ }^{26}$ Capacity credit is a metric to help understand a resource's contribution to time periods of interest, such as top 100 peak load hours. It represents the possible resource contribution of a power system asset as a percentage of its nameplate rating. The industry has provided a range of values for capacity credit and factor in the U.S. Northeast ranging from 38\% (NYISO 2018b) ${ }^{27}$ to $40 \%$ in NYISO (Ensslin et al. 2008). GE Power (2010) estimated capacity credit to range between $47 \%$ and $51 \%$ in a scenario with the best-suited wind sites for development in ISO-NE. These values can be compared in magnitude amongst each other, although hold different methodologies and varying peak hours of interest to make meaningful direct comparisons. In general, offshore wind has been observed to correlate with peak load hours relatively well compared to other VRE generation. One of the factors for a relatively high capacity credit of offshore wind generation resource is sometimes attributed to the "sea breeze effect" (see e.g., Dvorak et al. 2013).

This study assessed capacity credit by analyzing the capacity factor of offshore wind resource during the top 100 peak net load hours. Given the notable integration of solar PV and land-based wind in the U.S. Northeast, this study aimed to find the reliability contribution of offshore wind in possible futures that included other VRE sources. Net load in this study represents load with generation from solar PV and land-based wind resources subtracted. Table 7 shows a range of $21.5 \%(7 \mathrm{GW})$ to $28.3 \%(2 \mathrm{GW})$ capacity factor for offshore wind connected to ISO-NE and $14.5 \%(7 \mathrm{GW})$ to $27.1 \%(2 \mathrm{GW})$ in offshore wind connected to NYISO. Note that this analysis was limited to studying one year of wind resource data, weather year 2012. Extending to a longer time period would allow for further validation of the external validity of these findings. The joint consideration of offshore wind and other VRE capacity is conjectured to have resulted in a lower capacity credit of offshore wind than other analyses (see e.g., those listed above) have previously found. These other studies have commonly adopted load profiles without consideration for projected capacities of solar PV and land-based wind in a future power system representation. This divergent approach can result in a different peak hour and demand profile: as illustrated in Figures A-1 and A-2, the average capacity factor of offshore wind tends to decrease in the later afternoon and early evening hours, while higher solar PV penetrations will tend to push peak net load periods into these hours.

If capacity factor is considered during the top 100 peak hours (instead of during the top 100 peak net load hours), we observe a decrease in capacity factor as offshore wind penetration increases from $2 \mathrm{GW}$ to $7 \mathrm{GW} .{ }^{28}$ It should be noted that, unlike the equivalent firm capacity metric presented in the previous section, a top hour capacity factor approximation does not consider the impact of newly added VRE resources on shifting peak net load hours to times of lower VRE availability, which further decreases the marginal capacity credit of subsequently added resources. Figure A-1 and Figure A-2 show the top 100 peak load (pre-offshore wind) hours and corresponding offshore wind capacity factor during those hours.

\footnotetext{
${ }^{26}$ Note that "even the availability of thermal or conventional generation is not assured at all times because there is always a nonzero risk of mechanical or electrical failure" (Ensslin et al. 2008).

${ }^{27}$ This value represents the NYISO calculated unforced capacity percentage for offshore wind in Zone K during the summer and winter period.

${ }^{28}$ This may be largely a result of the method of selecting offshore wind resource sites, in the order of highest economic viability (Beiter et al. 2017), rather than selecting sites based on their ability to meet peak demand.
} 
Table 7. Capacity Credit Estimates for Combined ISO-NE and NYISO System using Top 100 Peak Net Load (Pre-Offshore Wind) Hours Methodology

\begin{tabular}{|c|c|c|c|c|c|}
\hline \multirow{2}{*}{ Method } & \multirow{2}{*}{$\begin{array}{c}\text { Metric } \\
\text { (Units) }\end{array}$} & \multirow{2}{*}{$\begin{array}{c}\text { Model } \\
\text { Year }\end{array}$} & Scenario & \multicolumn{2}{|c|}{$\begin{array}{c}\text { Average Gross Capacity Factor During Top 100 } \\
\text { Peak Hours }\end{array}$} \\
\cline { 4 - 6 } & & & Base (0 GW) & ISO-NE & NYISO \\
\cline { 4 - 6 } & & $2 \mathrm{GW}$ & $28.3 \%$ & $27.1 \%$ \\
\hline $\begin{array}{c}100 \text { top peak } \\
\text { hours }\end{array}$ & \multirow{2}{*}{ Hours } & 2024 & $7 \mathrm{GW}$ & $21.5 \%$ & $14.5 \%$ \\
\cline { 4 - 6 } & & & & & N \\
\hline
\end{tabular}

\subsection{System Production Costs and Wholesale Electricity Prices}

The PLEXOS model simulates system operation by modeling generators and their costs, transmission network and constraints, and optimizing to minimize costs while serving demand. The price is set by the marginal generator unit that is needed to satisfy electricity demand in each hour and is represented by the locational marginal price (LMP). VRE usually requires a capitalintense upfront investment but has relatively low operating and fuel expenses in comparison to thermal generators (e.g., coal, NGCC, NGCT, fuel oil). As a result, VRE generation, such as offshore wind, enters the merit-order bid stack at a marginal cost that is at or close to zero. This can displace the formerly price-setting marginal generator unit, resulting - all else being equal - in a reduction in the prevailing wholesale electricity price and system production costs.

\subsubsection{Wholesale electricity prices}

In this analysis, we calculated the impact on LMP under the various offshore wind scenarios by comparing median LMP in relation to the base case $(0 \mathrm{GW})$, as shown in Figure 9 . With the exception of the 2-GW scenario in NYISO, additional offshore wind capacity reduces the prevailing median LMP in comparison to the base case. ${ }^{29}$ These reductions are more pronounced in ISO-NE than NYISO. Median LMP reductions range from $-1 \%(2 \mathrm{GW})$ to $-13 \%(7 \mathrm{GW})$ in ISO-NE and $+1 \%(2 \mathrm{GW})$ to $-6 \%(7 \mathrm{GW})$. The average reduction in median LMP in the $7-\mathrm{GW}$ scenario across the two ISO areas ${ }^{30}$ is nearly $-11 \%$ compared to the base scenario. Median LMP calculation can suppress the occurrences of outliers; however, it still serves as a metric to show potential changes in wholesale electric costs to the U.S. Northeast. LMP does not include other monetized benefits, such as capacity value and flexibility services.

\footnotetext{
${ }^{29}$ This increase in LMP under the NYISO 2-GW scenario may be the result of changes in net exports, which grow as the prescribed offshore wind capacity level grows.

${ }^{30}$ Capacity-weighted average.
} 

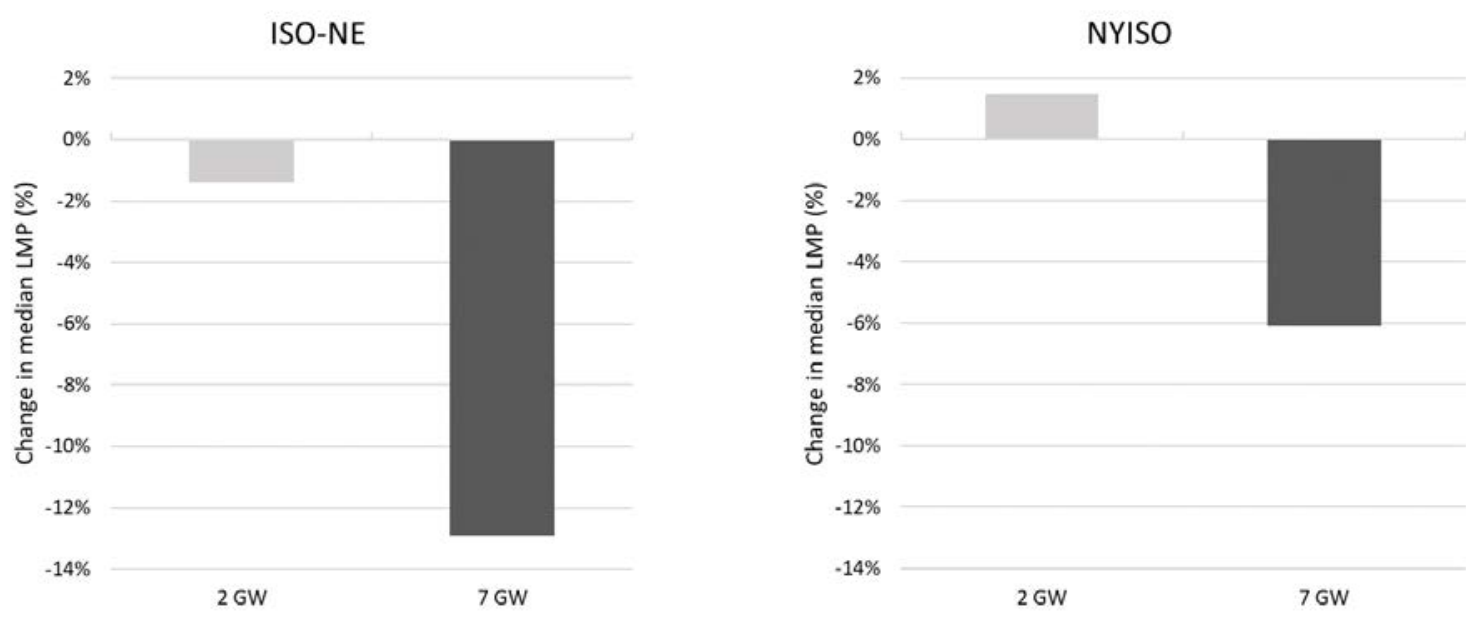

Figure 9. Differences in LMP in comparison to the base $(0 \mathrm{GW})$ scenario

Figure 10 shows the frequency of "near-zero" LMPs for the studied scenarios. Increasing amounts of offshore wind resource (at $\$ 0 / \mathrm{MWh}$ marginal cost) introduce a higher number of near-zero hourly LMPs, which are defined in this analysis as LMPs between $-\$ 1 / \mathrm{MWh}$ and $+\$ 1 / \mathrm{MWh}$. This may result in various generator types with nonzero marginal costs facing a higher likelihood of not being able to recover their fuel and operating costs, which leads to the shift in the ISO-NE and NYISO generation dispatch (Section 2.1) and the decrease in total power system production costs (Section 2.5.2).
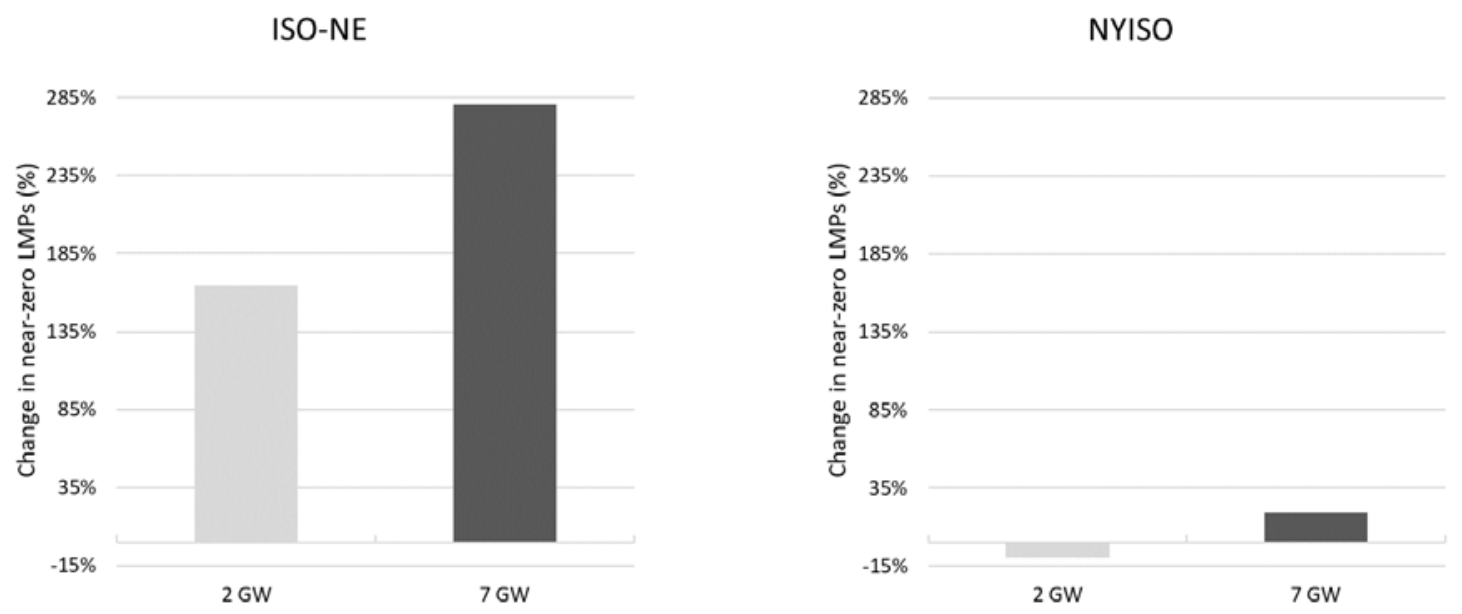

Figure 10. Change in near-zero LMPs

\subsubsection{System production costs}

Production costs are an indication of the total variable cost to produce electricity, based on generator heat rates, fuel prices, start-up costs, and variable operation and maintenance costs, subject to transmission and reserves constraints. This simulation minimizes production cost as it determines hourly generator dispatch during the year 2024. 
Figure 11 shows the production cost changes resulting from adding $2 \mathrm{GW}$ and $7 \mathrm{GW}$ of offshore wind in comparison to the $0-\mathrm{GW}$ scenario. They are shown without (left graph) and with (right graph) the cost of importing electricity into the ISO-NE and NYISO control areas. Because ISONE and NYISO are both net import regions, their load is partially served by external generators. The import costs were calculated by multiplying the imported energy (MW) with local ISO-NE or NYISO locational marginal price at the time of import. Without consideration for import costs, the results show nearly 5\% production cost savings, with $2 \mathrm{GW}$ of offshore wind, and $16 \%$ production cost savings, with $7 \mathrm{GW}$ of offshore wind, in comparison to the base scenario.

Additionally, when considering total production cost to serve demand in the Northeast, there's an additional $2 \%$ production cost savings in the $7-\mathrm{GW}$ scenario from decreased imports, resulting in more than $18 \%$ of production cost savings.

\section{U.S. Northeast Without Import Costs Considered}

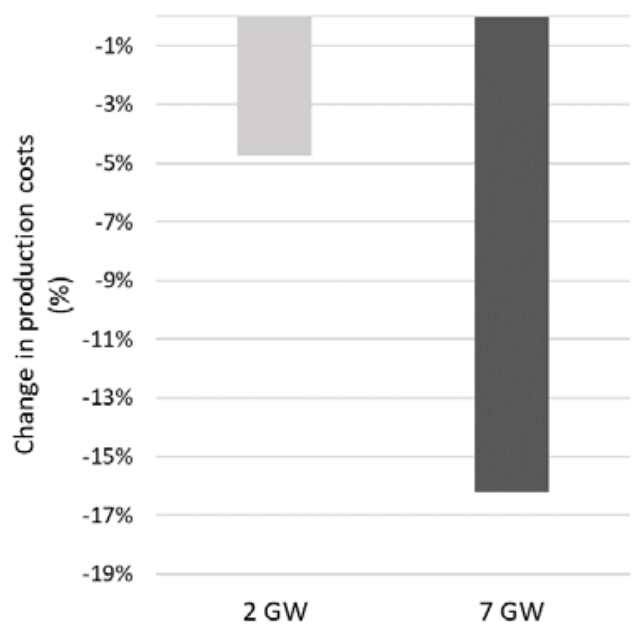

U.S. Northeast with Import Costs Considered

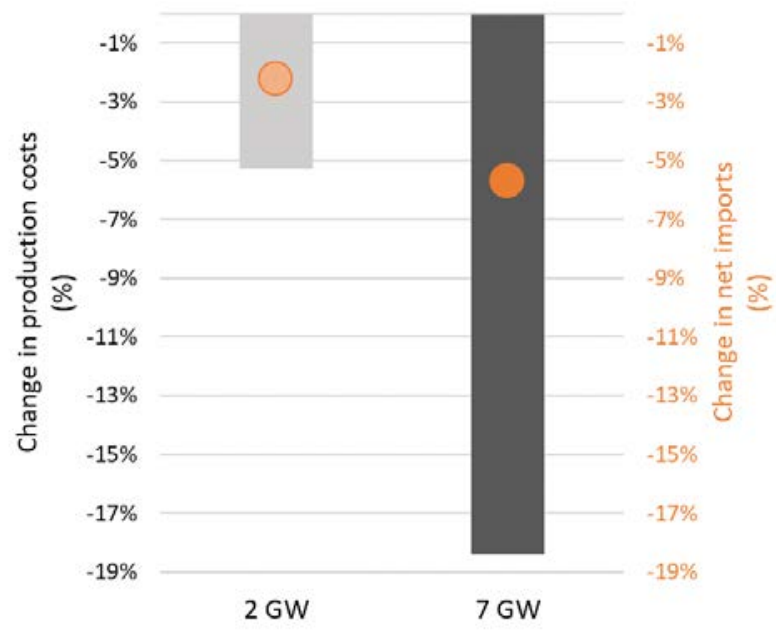

Figure 11. Differences in system production costs in comparison to the $0-G W$ (base) scenario

These reductions in system production costs are a monetary representation of the impacts of offshore wind. However, this study should not be considered a cost-benefit analysis, as it does not include any fixed cost, such as capital and interconnection costs of integrating offshore wind, or other potential revenue streams or tax benefits.

\subsection{Interface Flows and Congestion}

Because of its proximity to coastal load centers in the United States, offshore wind is commonly thought of as a resource that has the potential to relieve transmission constraints. As offshore wind is injected at the identified coastal POI (Section 1.4) in this study, transmission flows between different interface points change systemwide in the U.S. Northeast. In the 2-GW scenario, there are increased interface flows from Rhode Island into southeast Massachusetts and Connecticut, whereas interface flows decrease from the greater Boston area and Connecticut into Rhode Island and from southern New York (Zone I) into New York City (Zone J) compared to the $0-\mathrm{GW}$ scenario because of increased offshore wind energy injected in coastal load areas (Figure 12). 


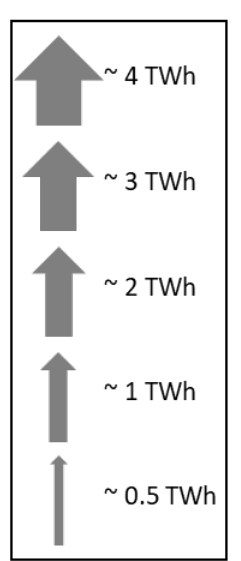

Note: Only interface flows > 0.1 TWh shown; interface flows rounded to nearest arrow size

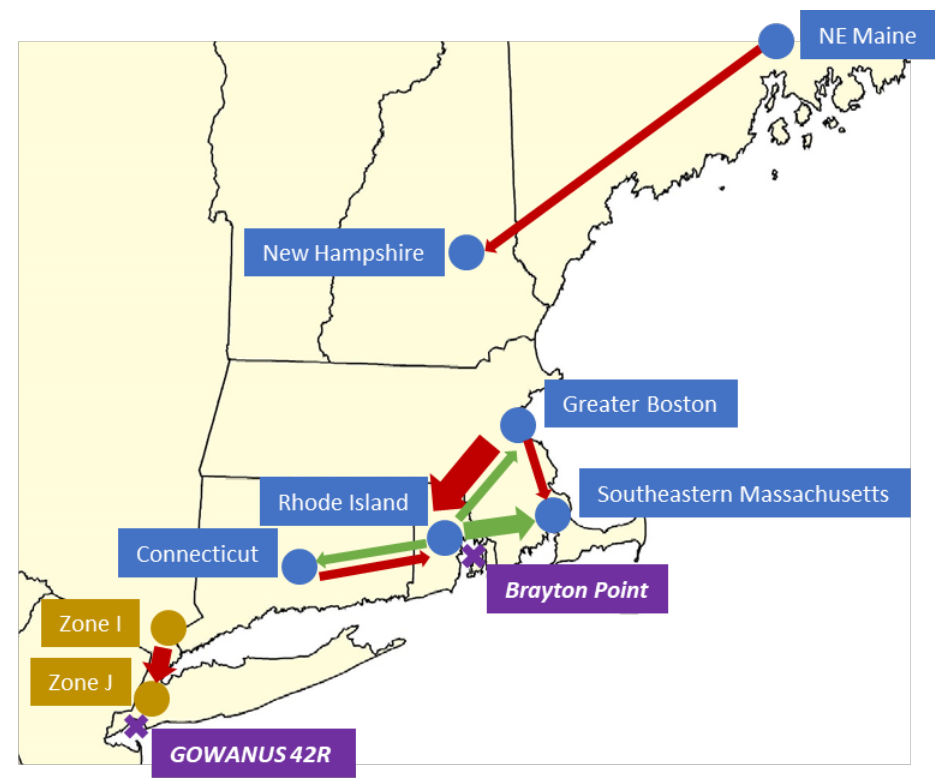

Figure 12. Difference in interface flows in U.S. Northeast between the 2GW and 0-GW scenarios

Note: Red arrows indicate a reduction in interface flows; green arrows indicate an increase in interface flows; ISO-NE interface points shown in yellow; NYISO interface shown in blue; points of offshore wind interconnection shown in purple.

In the 7-GW 2024 scenario, some of the interface flow trends that were identified for the 2-GW scenario intensify as a result of increased offshore wind capacity (Figure 13). Interface flows grow larger from Rhode Island into the greater Boston area and southeast Massachusetts. There is a high volume of interface flows from Connecticut to Rhode Island and in smaller volume into Zone G. In NYISO, there is a large volume reduction in interface flows from southern New York (Zone I) to New York City (Zone J) and from New York City (Zone J) to Long Island (Zone K). Interface flows from northeast Maine into New Hampshire and from Quebec into northern New York (Zone E) decrease. ${ }^{31}$

\footnotetext{
${ }^{31}$ NYISO and ISONE are net importers of electricity, and a major source of those imports are from Canada. The Quebec - Zone E interface is not shown in Figure 12 because there is no change in Canadian imports in the 2-GW scenario. In the 7-GW scenario, the amount of imports from Quebec slightly decreases. Because the energy coming from Quebec is largely hydro generation (at very low marginal cost), this energy does not start to be displaced until the 7-GW scenario.
} 


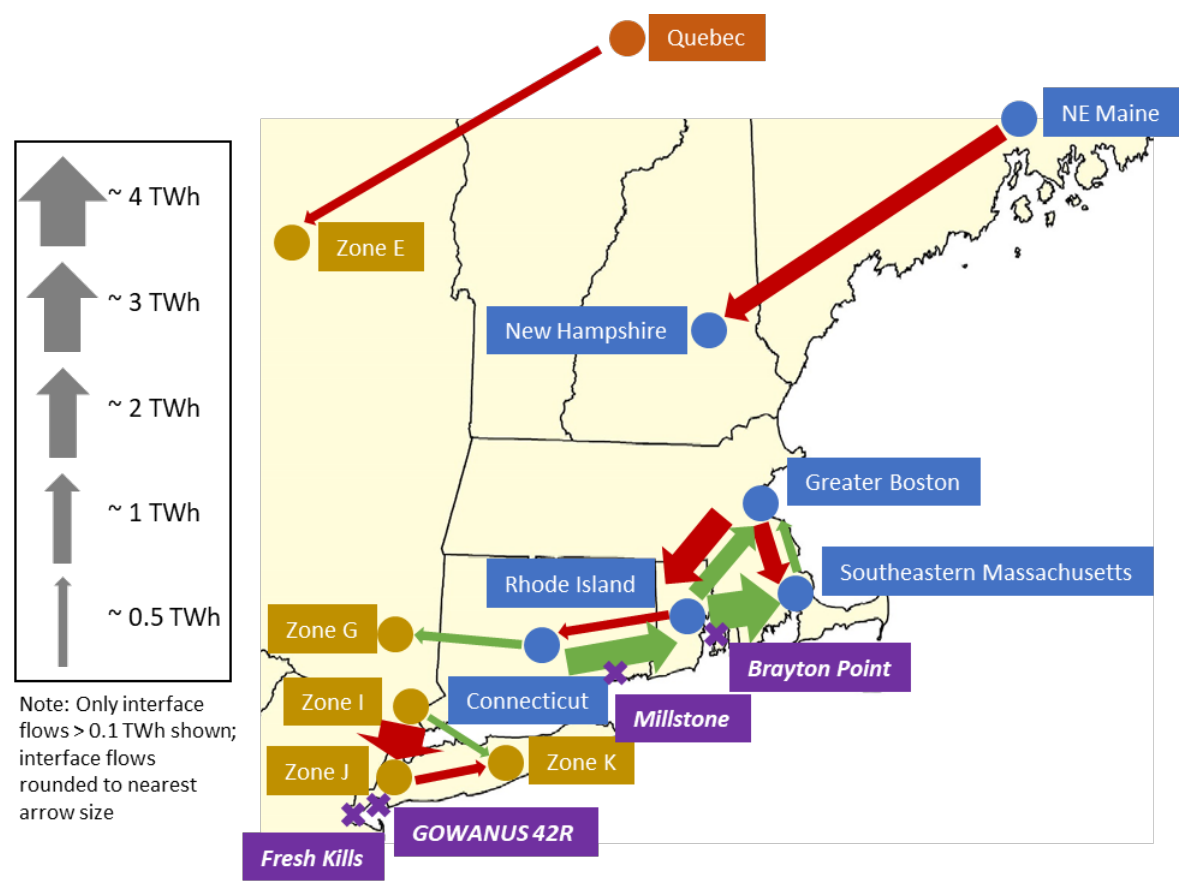

Figure 13. Difference in interface flows in U.S. Northeast between the 2024 7-GW and 0-GW (base) scenarios

Note: Red arrows indicate a reduction in interface flows; green arrows indicate an increase in interface flows; ISO-NE interface points shown in yellow; NYISO interface shown in blue; points of offshore wind interconnection shown in purple.

The number of congested hours changes between several interface pairs (Figure 14) without a consistent directional trend, which results in a net increase of total congested hours of $+1 \%$ in the $2-\mathrm{GW}$ and $+4 \%$ in the $7-\mathrm{GW}$ scenarios as compared to the $0-\mathrm{GW}$ (base) scenario. This is the result of a combination of the selected points of offshore wind interconnection, the offshore wind (WIND Toolkit) generation profiles, and their coincidence with the broader system production and demand profiles. The increase in congested hours as offshore wind is injected is most pronounced between the interfaces in southern New York (Zone I) and Long Island (Zone K) ( $+9 \%$ under the $7-\mathrm{GW}$ scenario). This interface pair is already highly congested in the 0 -GW (base) scenario, with nearly 3,000 congested hours). Conversely, there is a reduction in congested hours between upstate New York (Zone E) and Quebec (-1.9\% in the 7-GW scenario). Although the number of congested hours decrease for the interface pair Connecticut-Long Island (Zone $\mathrm{K}$ ) under the $2-\mathrm{GW}$ scenario by $-1.2 \%$, they increase under the $7-\mathrm{GW}$ scenario $(+0.8 \%)$ in comparison to the $0-\mathrm{GW}$ (base) scenario. 


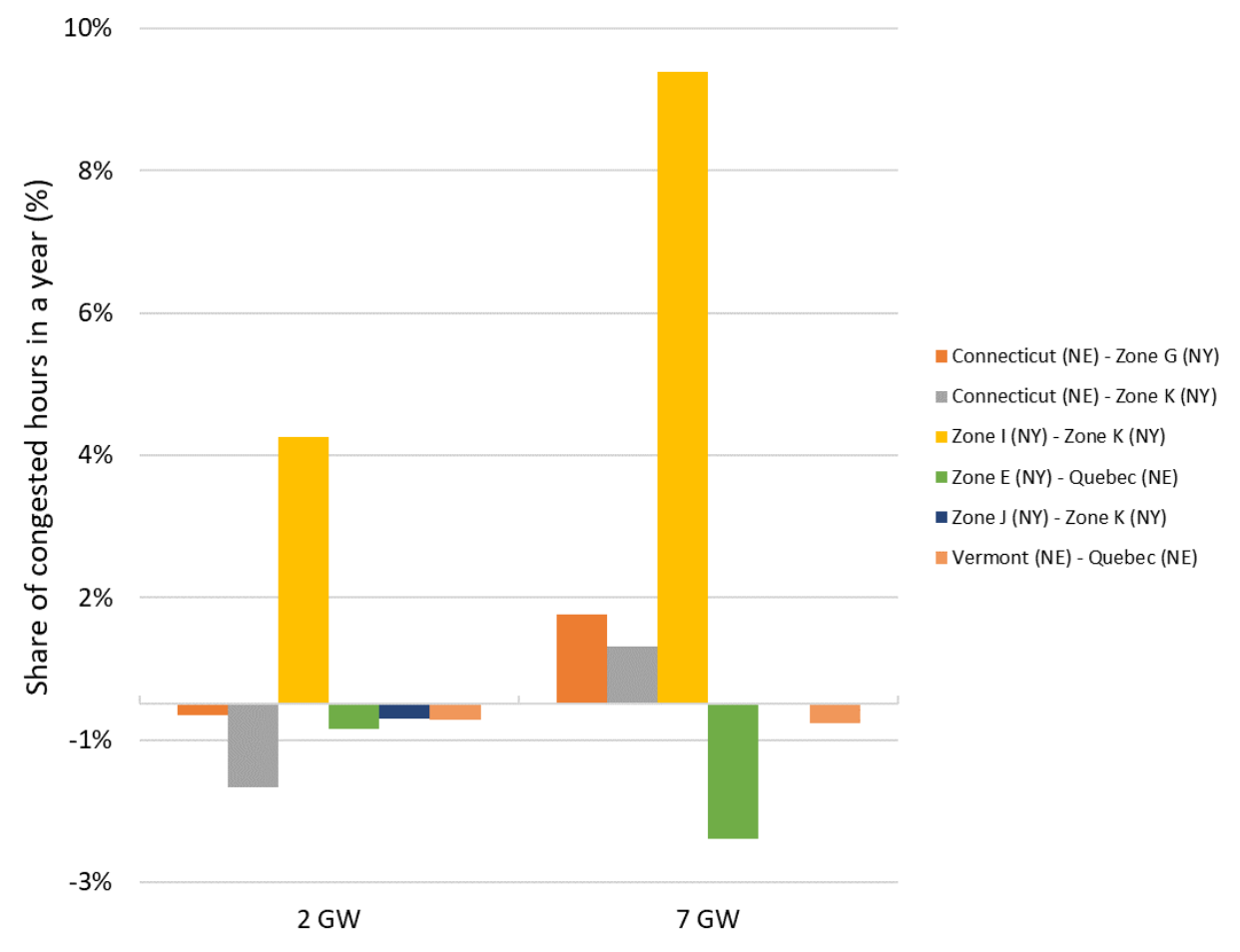

Figure 14. Share of congested hours in the U.S. Northeast (2-GW and 7-GW scenarios)

Note: Only interface pairs shown that have congested hours different from 0.

\subsection{Curtailment Rates of Offshore Wind Generation}

Curtailment rates for offshore wind generation in ISO-NE and NYISO were estimated to range between 3.2\% and 5.8\% (Figure 15). These values are above the general range of curtailment rates for land-based wind observed in ISO-NE and NYISO in recent years (Beiter et al. 2018b). Under the 2- and 7-GW scenario, the average curtailment rates in ISO-NE and NYISO combined $^{32}$ is approximately $4 \%$ and $5 \%$, respectively. This compares to an estimated average curtailment rate of $9.3 \%$ (land-based wind) and $4.3 \%$ (solar PV) in the 7-GW scenario.

All else constant, curtailment rates of offshore wind (and other VRE generation sources) are generally expected to increase coincident with higher VRE penetration levels. In a power system where similar generation patterns prevail (e.g., from VRE), supply tends to exceed load more frequently and induce ISO-instructed or economic curtailment. In ISO-NE, the curtailment rate of offshore wind generation grows with increasing offshore wind capacity. However, in NYISO, offshore wind curtailment rates decline as the offshore wind capacity rises. This counter-intuitive finding is likely a result of the combined impact from changing interface flows and a different set of offshore wind resource sites considered under the 2- and 7-GW scenarios. In addition, based on the assumed locations of offshore wind interconnection in this study, the point of interconnection of offshore wind energy into NYISO is geographically near a high load center,

${ }^{32}$ Capacity-weighted average. 
the New York City region. The ISO-NE offshore wind interconnection sites are geographically further from high load centers, such as Boston. Therefore, offshore wind injections in ISO-NE rely more heavily on the transmission infrastructure contributing to higher congestion and possible curtailment.
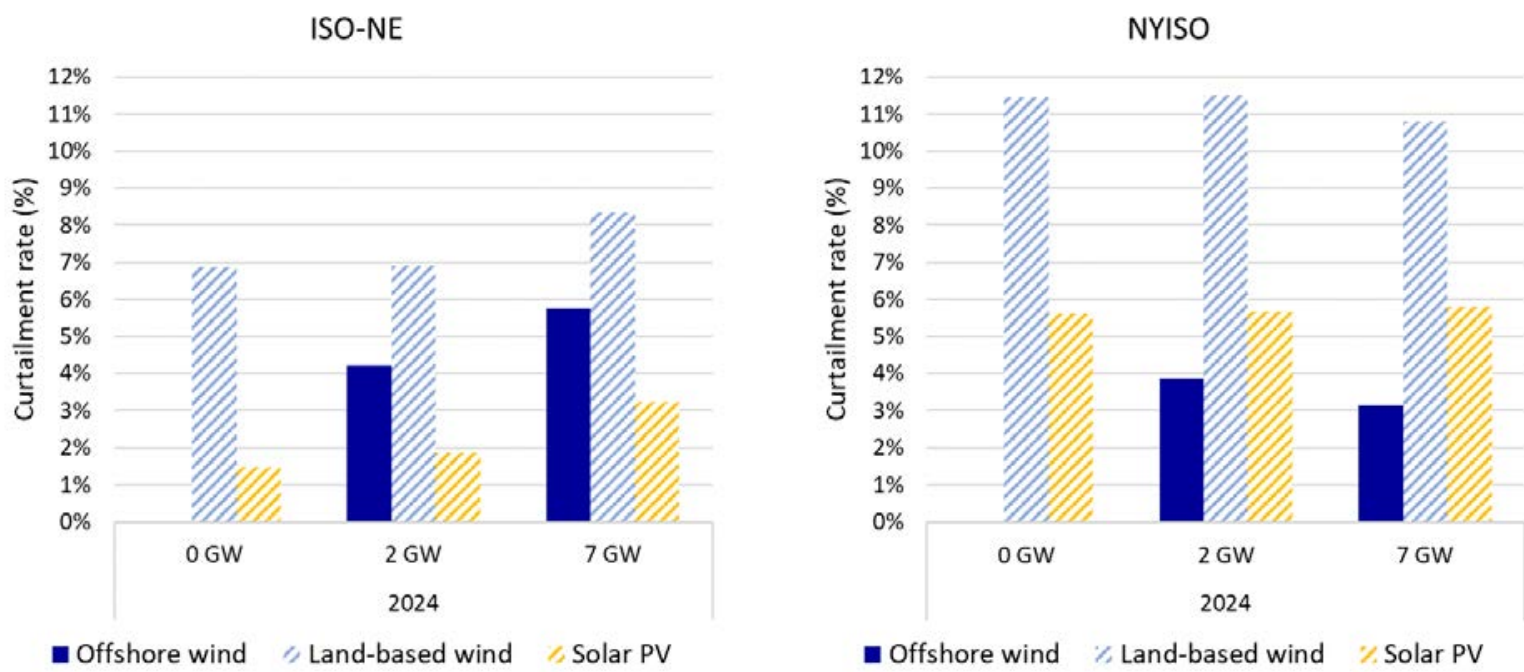

Figure 15. Curtailment rates of offshore wind generation 


\section{Limitations}

This study is an assessment of possible impacts from offshore wind injection to the ISO-NE and NYISO power system operations based on the assumptions, methodologies, and data sources documented in this report. In general, production cost models and results are useful tools to inform long-term planning by comparing scenarios and understanding different impacts on KPIs. However, they should not be taken in absolute value as many assumptions on the future scenarios can drive results. This can be improved by running additional future scenarios and capturing a larger data set of load, offshore wind, and other resources.

This impact study should not be considered a cost-benefit analysis, as we did not calculate or consider the cost of constructing, interconnecting, or other necessary system upgrades. Generation resources can also have other revenue streams, such as capacity market payments and production tax credits, which were not included in this study. Offshore wind was connected to the study system with a power systems representation that considers existing points of interconnection based on a "minimum upgrade approach." Production cost models also do not reflect necessary interconnection and operational requirements in an alternating-current system, such as dynamics and stability. In addition to these general modeling limitations, some important caveats to this study include:

- Several KPIs, such as LOLE, have been found to be highly sensitive to the chosen POI location and transmission constraints. The chosen coastal POI were found to be generally capable of delivering most of the resource energy. Assessing POI through energy and resource adequacy models can better identify locations that best provide system benefits.

- The offshore wind generation profile data from 2012 (sourced from the WIND Toolkit) represents a single weather year. Although 2012 was found to be a normal weather year for load, this can limit the inferences that can be made from the presented results onto other years. Further validation of the offshore wind resource data is also necessary to provide a more robust data basis for the inferences made.

- Interconnecting offshore wind, even at retiring power plant sites, is complex and requires additional impact studies, including dynamic and stability studies.

- Higher O\&M costs incurred by thermal plants (e.g. NGCCs) because of increased cycling to accommodate the prescribed offshore wind capacities are not considered (e.g., as part of system production costs).

- The power system analyzed in this study was derived based on a set of assumptions and data input and does not necessarily represent a future power system configuration. For instance, improvements in forecasting, maintaining flexible system resources, and subhourly markets may improve a system operators' ability to respond to changing system conditions. Comprehensive transmission and interconnection planning can help optimize the power system as new generation resources, such as offshore wind, are added. 


\section{Conclusions}

We found that the power system representation for 2024 implemented in this study for the combined ISO-NE and NYISO control areas can accommodate offshore wind capacity injections of $2 \mathrm{GW}$ and $7 \mathrm{GW}$. Injecting offshore wind into the modeled U.S. Northeast power system changes power system operations. In turn, this leads to the following key impacts:

- Curtailment levels of offshore wind remain relatively low in the combined ISO-NE and NYISO control areas, with $4.1 \%$ under the 2-GW scenario; after interconnecting $7 \mathrm{GW}$ of offshore wind nameplate capacity curtailment levels increase by $0.8 \%$ to nearly $5 \%$.

- Offshore wind primarily displaces generation from NGCC and NGCT. However, because of increased variability in the net load, NGCC experiences increased starts and decreased hours on-line per start, thereby indicating more frequent cycling.

- Offshore wind injection at the selected coastal POI changes interface flows in the U.S. Northeast, with some relief in coastal load centers in the greater Boston and NYC areas. However, the total number of congested hours increases coincidentally as offshore wind generation flows to load areas in the incremental offshore wind scenarios considered.

- The contribution from offshore wind to resource adequacy was found to be in the range of $14.5 \%-28.3 \%$ for capacity credit, which is lower than determined in other studies that use different methods for the U.S. Northeast. This may be due in part to differing solar PV and onshore wind penetration assumptions between studies, which can shift the system's peak net load hours. Further research is needed in this area to allow for better comparison between studies.

- Injecting offshore wind at a marginal cost of $\$ 0 / \mathrm{MWh}$ in the U.S. Northeast leads to a change in median LMP of $0 \%(2 \mathrm{GW})$ and $-11 \%(7 \mathrm{GW})$ compared to the $0-\mathrm{GW}$ scenario; total system production costs decrease by $5 \%(2 \mathrm{GW})$ and $16 \%(7 \mathrm{GW})$ compared to the $0-\mathrm{GW}$ scenario (without considering import costs).

Weighing these impacts relative to other types of generation can help provide a better understanding of the benefits and disadvantages of offshore wind under various system conditions (see e.g., Mills et al. 2018). Further work will need to analyze some of the power system dynamics identified in this study and provide additional sensitivities, particularly on the points of offshore wind interconnection and under consideration of additional offshore wind resource data. 


\section{References}

ABB. 2014. National Offshore Wind Energy Grid Interconnection Study. Accessed September 2018. https://www.energy.gov/eere/downloads/national-offshore-wind-energy-gridinterconnection-study-nowegis.

ABB. 2018. ABB Ability Velocity Suite. Subscription-based software. Accessed under ABB license in 2017/2018.

Bloom, A., A. Townsend, D. Palchak, J. Novacheck, J. King, C. Barrows, E. Ibanez, M. O'Connell, G. Jordan, B. Roberts, C. Draxl, K. Gruchalla. 2016. Eastern Renewable Generation Integration Study. NREL/TP-6A20-64472. https://www.nrel.gov/docs/fy16osti/64472.pdf.

Beiter, Philipp, Walter Musial, Levi Kilcher, Michael Maness, and Aaron Smith. 2017. "An Assessment of the Economic Potential of Offshore Wind in the United States from 2015 to 2030.” NREL/TP-6A20-67675. Golden, CO: National Renewable Energy Laboratory. https://www.nrel.gov/docs/fy17osti/67675.pdf.

Beiter, P., P. Spitsen, J. Nunemaker, T. Tian, W. Musial, E. Lantz, V. Gevorgian. 2018a. "2017 Offshore Wind Technologies Market Update." U.S. Department of Energy Office of Energy Efficiency and Renewable Energy. Accessed September 2018. https://www.energy.gov/sites/prod/files/2018/08/f54/71709_0.pdf.

Beiter, P., N. Vincent, O. Ma. 2018b. "2016 Renewable Energy Grid Integration Data Book." U.S. Department of Energy Office of Energy Efficiency and Renewable Energy. DOE/GO102018-5081. Accessed September 2018. https://www.nrel.gov/docs/fy18osti/71151.pdf.

California Independent System Operator. 2018. "What the duck curve tells us about managing a green grid.” Accessed September 2018. https://www.caiso.com/documents/flexibleresourceshelprenewables fastfacts.pdf.

Cole, W., T. Mai, J. Logan, D. Steinberg, J. McCall, J. Richards, B. Sigrin, G. Porro. 2016. 2016 Standard Scenarios Report: A U.S. Electricity Sector Outlook. NREL/TP-6A20-66939. https://www.nrel.gov/docs/fy17osti/66939.pdf.

Dent, C., and S. Zachary. 2013. "Capacity Value of Additional Generation: Probability Theory and Sampling Uncertainty.” Accessed September 2018. https://arxiv.org/pdf/1305.6479v1.pdf.

Draxl, C., A. Clifton, B. Hodge, J., McCaa. 2015. "The Wind Integration National Dataset (WIND) Toolkit." Applied Energy, 151: 355-366. Accessed September 2018. https://www.sciencedirect.com/science/article/pii/S0306261915004237.

Dvorak, M., B. Corcoran, J. Hoeve, N. McIntyre, M. Jacobsen. 2013. "US East Coast offshore wind energy resources and their relationship to peak-time electricity demand." Wind Energy 2013 (16): 977-997. https://onlinelibrary.wiley.com/doi/abs/10.1002/we.1524.

Ensslin, C., M. Milligan, H. Holttinen, M. O’Malley, A. Keane. 2008. "Current methods to calculate capacity credit of wind power, IEA collaboration." Paper presented at the Power and 
Energy Society General Meeting - Conversion and Delivery of Electrical Energy in the 21st Century, Pittsburgh, PA, July 20-24, 2008.

https://www.researchgate.net/publication/4361034_Current_methods_to_calculate capacity_cre dit_of_wind_power_IEA_collaboration.

Federal Energy Regulatory Commission. 2016. "Form No. 714 - Annual Electric Balancing Authority Area and Planning Area Report." https://www.ferc.gov/docs-filing/forms/form714/data.asp.

General Electric (GE) Power. 2010. New England Wind Integration Study. Prepared for ISO New England. GE Energy, Schenectady, NY (US). https://www.iso-ne.com/staticassets/documents/committees/comm_wkgrps/prtcpnts_comm/pac/reports/2010/newis_report.pdf.

Hodge, B. 2016. "Final Report on the Creation of the Wind Integration National Dataset (WIND) Toolkit and API. National Renewable Energy Laboratory (NREL), Golden, CO. NREL/SR5D00-66189. Accessed September 2018. https://www.nrel.gov/docs/fy16osti/66189.pdf.

ISO New England. 2016. "2015 Economic Study Evaluation of Offshore Wind Deployment." September 2, 2016. Accessed September 2018. http://www.iso-ne.com/staticassets/documents/2016/09/2015_economic_study_offshore_wind_development_final.docx.

ISO New England. 2017. “2017 Forecast Data File.” Accessed September 2018. https://www.iso-ne.com/static-assets/documents/2017/05/forecast_data_2017.xlsx.

ISO New England. 2018. "High-Level Assessment of Potential Impacts of Offshore Wind Additions to the New England Power System During the 2017-2018 Cold Spell" Accessed November 2019. https://www.iso-ne.com/static-assets/documents/2018/12/2018 isone_offshore_wind_assessment_mass_cec_production_estimates_12_17_2018_public.pdf.

Massachusetts Clean Energy Center. 2014. "Offshore Wind Transmission Study.” Prepared by ESS Group, Inc. Accessed September 2018. https://www.masscec.com/offshore-windtransmission-study.

Mills, A., D. Millstein, S. Jeong, L. Lavin, R. Wiser, M. Bolinger. 2018. "Estimating the value of offshore wind along the United States' Eastern Coast." Environmental Research Letters, 13: 112. Accessed September 2018. http://iopscience.iop.org/article/10.1088/1748-9326/aada62/meta.

Musial, Walter, Philipp Beiter, Paul Schwabe, Tian Tian, Tyler Stehly, and Paul Spitsen. 2017. "2016 Offshore Wind Technologies Market Report." Technical Report. Washington, D.C.: U.S. Department of Energy Office of Energy Efficiency \& Renewable Energy. https://www.energy.gov/sites/prod/files/2017/08/f35/2016\%20Offshore\%20Wind\%20Technolog ies\%20Market\%20Report.pdf.

Musial, Walter, Philipp Beiter, Paul Spitsen, Jake Nunemaker, Vahan Gevorgian. 2019. "2018 Offshore Wind Technologies Market Report.” Technical Report. Washington, D.C.: U.S. Department of Energy Office of Energy Efficiency \& Renewable Energy. https://www.energy.gov/sites/prod/files/2019/09/f66/2018\%20Offshore\%20Wind\%20Technolog ies\%20Market $\% 20$ Report.pdf. 
National Renewable Energy Laboratory. 2011. "Eastern Wind Integration and Transmission Study.” Report prepared by EnerNex Corporation. NREL/SR-5500-47078. Accessed September 2018. https://www.nrel.gov/docs/fy11osti/47078.pdf.

National Renewable Energy Laboratory. 2018. "Geospatial Data Science Modeling." Accessed September 2018. https://www.nrel.gov/gis/modeling.html.

North American Electric Reliability Corporation. 2018. Probabilistic Adequacy and Measures. Technical Reference Report. Accessed September 2018. https://www.nerc.com/comm/PC/PAWG\%20DL/Probabilistic_Adequacy_and_Measures_Report draft_05142018.pdf.

New York Independent System Operator (NYISO). 2017. "2016 Load \& Capacity Data (Gold Book)." Accessed September 2018. www.nyiso.com/public/...and.../2016 Load Capacity Data Report.pdf.

NYISO. 2018a. "Power System Fundamentals." New York Market Orientation Course, September 18-21, 2018. Accessed September 2018. https://www.nyiso.com/public/...MT.../Power_Systems_Fundamentals.pdf.

NYISO. 2018b. "Installed Capacity Manual (Manual 4, Version 6.39)." Accessed September 2018. www.nyiso.com/public/webdocs/markets.../Manuals...Guides/Manuals/../icap_mnl.pdf.

Rossol, M., Brinkman, G., Buster, G., Denholm, P., Novacheck, J., and Stephen, G.. "An Analysis of Thermal Plant Flexibility Using a National Generator Performance Database." Environmental Science \& Technology 201953 (22), 13486-13494 https://pubs.acs.org/doi/pdf/10.1021/acs.est.9b04522

Stephen, G., B. Frew, D. Sigler, W. Jones. 2018. “Apples to Apples: Equivalent-Reliability Power Systems Across Diverse Resource Mix Scenarios.” Presentation at the UVIG 2018 Spring Technical Workshop, March 14, 2018, Tucson, AZ. NREL/PR-6A20-71175. https://www.nrel.gov/docs/fy18osti/71175.pdf.

U.S. Department of Energy. 2015. Wind Vision: A New Era for Wind Power in the United States. U.S. Department of Energy Office of Energy Efficiency and Renewable Energy. DOE/GO102015-4557. Washington, D.C. http://www.energy.gov/sites/prod/files/WindVision_Report_final.pdf.

Wilson. 2011. "Grid Congestion and LBMP Pricing: Barrier or Opportunity?" Presentation at American Wind Energy Association conference. 


\section{Appendix A}

\section{A-1. Points of Offshore Wind Interconnection}

To identify potential points of interconnection (POI), the authors conducted the following steps:

1. Assign offshore wind capacity under the 2-gigawatt (GW) (case I), 7-GW (case II) scenarios to the New York Independent System Operator (NYISO) and ISO-New England (ISO-NE) areas in proportion to the capacity of their estimated offshore wind project pipeline capacities as documented in Musial et al. (2017).

Table A-1. Offshore Wind Capacity Allocations to NYISO and ISO-NE Service Territories

\begin{tabular}{|l|l|l|}
\hline & Offshore Wind Capacity (GW) \\
\hline Scenario & ISO-NE & NYISO \\
\hline I & 1.33 & 0.67 \\
\hline II & 4.67 & 2.33 \\
\hline
\end{tabular}

2. Identify existing POI above 345 kilovolts and power plants scheduled for retirement by 2024 (Source: ABB 2018), where each are located less than 2 kilometers from coastline.

3. Choose the closest POI to the offshore wind resource. Exceptions were made for known interconnection points of offshore wind projects currently under development or in advanced planning phases. Use expert judgment and Wilson (2011) to select POI that are expected to lend themselves for offshore wind development in terms of their maximum capacity and technical feasibility.

\section{A-2. Offshore Wind Gross Capacity Factor During Top 100 Peak Hours}

\section{ISO-NE}

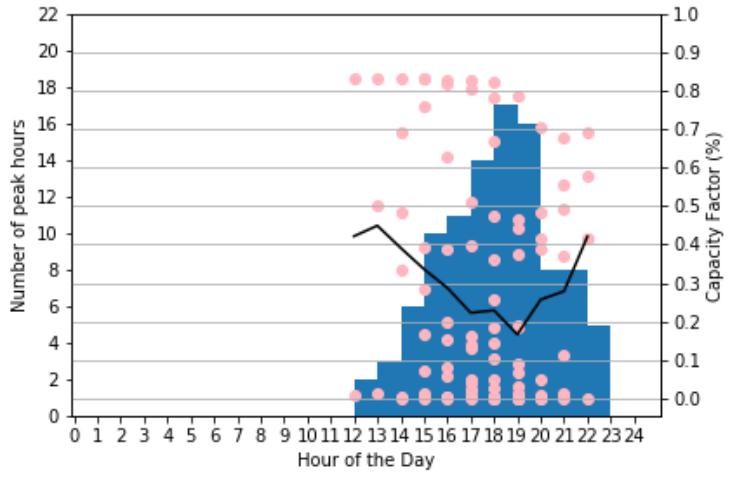

$2 \mathrm{GW}$

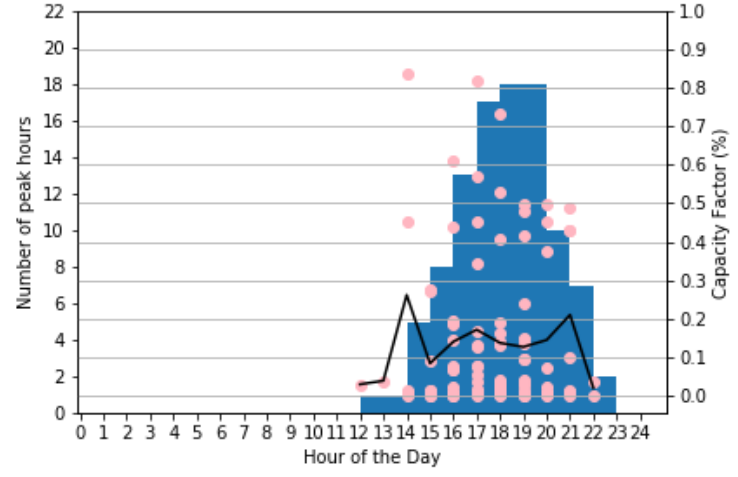

$7 \mathrm{GW}$

$$
\begin{aligned}
& \text { Avg capacity factor } \\
& \text { Individual capacity factor } \\
& \text { Count of peak hours }
\end{aligned}
$$

Figure A-1. Offshore wind gross capacity factor during top 100 peak hours in ISO-NE 


\section{NYISO}

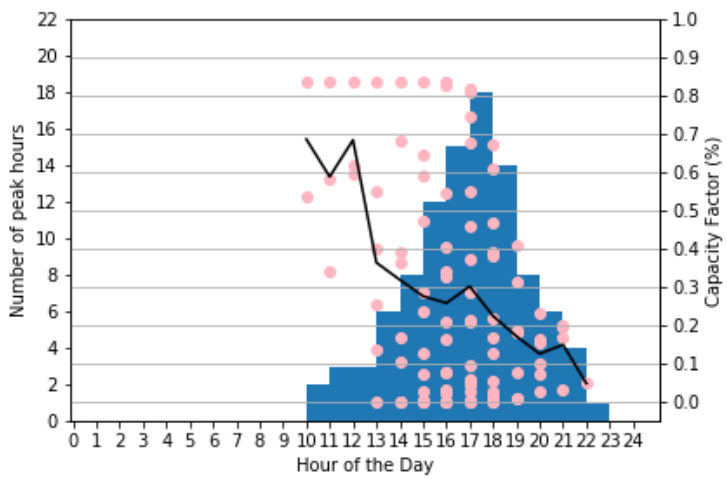

$2 \mathrm{GW}$

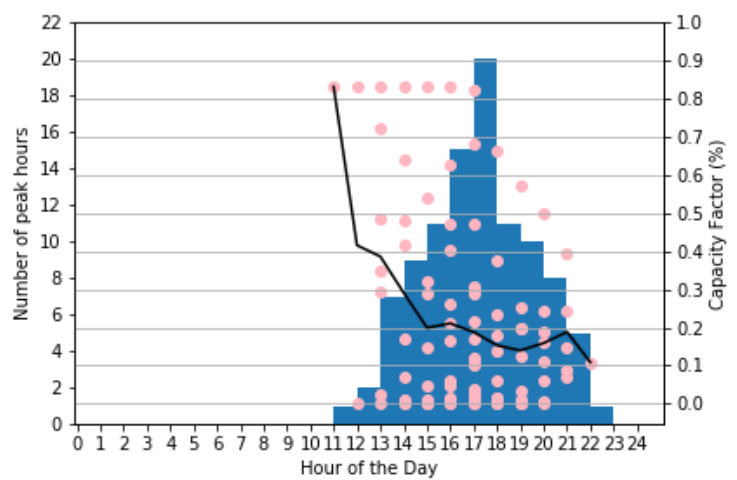

$7 \mathrm{GW}$

Avg capacity factor

Individual capacity factor

Count of peak hours

Figure A-2. Offshore wind gross capacity factor during top 100 peak hours in NYISO 